\title{
Exploring the uncharted waters of educational mobility: The role of key skills
}

Citation for published version (APA):

Jacobs, B., \& van der Velden, R. (2021). Exploring the uncharted waters of educational mobility: The role of key skills. Maastricht University, Graduate School of Business and Economics. GSBE Research Memoranda No. 016 https://doi.org/10.26481/umagsb.2021016

Document status and date:

Published: 15/11/2021

DOI:

10.26481/umagsb.2021016

Document Version:

Publisher's PDF, also known as Version of record

\section{Please check the document version of this publication:}

- A submitted manuscript is the version of the article upon submission and before peer-review. There can be important differences between the submitted version and the official published version of record.

People interested in the research are advised to contact the author for the final version of the publication, or visit the DOI to the publisher's website.

- The final author version and the galley proof are versions of the publication after peer review.

- The final published version features the final layout of the paper including the volume, issue and page numbers.

Link to publication

\footnotetext{
General rights rights.

- You may freely distribute the URL identifying the publication in the public portal. please follow below link for the End User Agreement:

www.umlib.nl/taverne-license

Take down policy

If you believe that this document breaches copyright please contact us at:

repository@maastrichtuniversity.nl

providing details and we will investigate your claim.
}

Copyright and moral rights for the publications made accessible in the public portal are retained by the authors and/or other copyright owners and it is a condition of accessing publications that users recognise and abide by the legal requirements associated with these

- Users may download and print one copy of any publication from the public portal for the purpose of private study or research.

- You may not further distribute the material or use it for any profit-making activity or commercial gain

If the publication is distributed under the terms of Article $25 \mathrm{fa}$ of the Dutch Copyright Act, indicated by the "Taverne" license above, 


\section{Maastricht University}

Babs Jacobs, Rolf van der Velden

Exploring the Uncharted Waters of Educational Mobility: The Role of Key Skills

$\mathrm{RM} / 21 / 016$

ISSN: $2666-8807$

\section{GSBE}

Maastricht University School of Business and Economics

Graduate School of Business and Economics

P.O Box 616

NL-6200 MD Maastricht

The Netherlands 


\title{
Exploring the Uncharted Waters of Educational Mobility: The Role of Key Skills
}

Babs Jacobs* \& Rolf van der Velden*1

*Maastricht University: Research Centre for Education and the Labour Market (ROA)

\begin{abstract}
For decades, researchers tried to get a deeper understanding of the intergenerational transmission of education to shed light on inequality of educational opportunities (IEO) that determine social mobility. The underlying drivers of IEO can stem from three types of parental resources: parent's key skills (i.e., proficiency in important domains like math and language), parent's soft skills (i.e., the skills needed to navigate successfully in education), and parent's financial resources. Previous research was not able to accurately distinguish between the contributions of these different resources, mainly because adequate data on the intergenerational transmission of key skills was missing. This study aims to fill this gap. We developed a unique and unparalleled dataset, the Intergenerational Transmission of Skills (ITS) dataset, combining key skills of more than 25,000 Dutch parents and their children measured with the same test at age 12 with detailed information on the educational pathways and household income. We demonstrate that parent's key skills is the most important mechanism driving IEO. One standard deviation increase in parent's key skills is associated with almost one-third of a standard deviation increase in the key skills of their offspring. The intergenerational transmission of key skills accounts for $50-60 \%$ of the effect of all measured resources available in the family. The role of financial resources available to the family is a bit stronger than the role of parent's soft skills, accounting for some $25-30 \%$ of the total effect of family resources, with parent's soft skills taking up some 20-25\%.
\end{abstract}

Keywords: inequality of educational opportunities, key skills, soft skills, financial resources, human capital, cultural capital, financial capital, intergenerational transmission of education

\footnotetext{
${ }^{1}$ Corresponding author: R.vanderVelden@maastrichtuniversity.nl
} 


\section{Introduction}

Intergenerational transmission of education is one of the key topics in stratification research (Ganzeboom, Treiman and Ultee 1991; Treiman and Ganzeboom 2000). A strong association between parents' and offspring's educational attainment reflects a high level of inequality of educational opportunities (IEO), while a weak association is indicative of a high degree of social mobility and openness of societies. The modernization theory predicted that as societies advance, social mobility would increase (Treiman 1970). Contrary to this expectation, historical comparisons in Western societies (e.g., Breen and Jonsson 2005; Breen and Müller 2020) have shown that this is still an uphill battle. In cohorts born in the second half of the $20^{\text {th }}$ century, the relative social mobility, the dependency between social origin and destination, remained stable and upward mobility even reduced. Given this pervasively strong IEO, understanding the mechanism underlying this intergenerational transmission of education between parents and their children is more important than ever.

Multiple mechanisms at the family level underlie IEO. First, key skills such as language and math skills are crucial to be successful in education. These skills form the basis for further skills development in education. Previous research showed that these skills are indeed highly predictive in terms of educational attainment (e.g., Fischbach et al. 2013; Knighton and Bussière 2006), but the intergenerational transmission of these skills and thus a potential mechanism underlying IEO has remained rather unexplored. It is likely that a large part of the intergenerational transmission of education is essentially a transmission of these key skills.

Second, there are also more subtle elements related to the educational attainment of parents that make their offspring successful in education and thus contribute to IEO. Educational sociologists have argued that soft skills, such as familiarity with the culture at school, knowledge of the educational system, feeling at home at school, and the acquisition of certain positive norms and values towards education, make it easier to successfully navigate through education (Barone 2006; Forster and Van de Werfhorst 2020; Kalmijn and Kraaykamp 1996; Kloosterman et al. 2009; Sullivan 2001). Parents differ in the extent to which they possess these soft skills and use it to help their children in their school career. Consequently, part of IEO can be attributed to differences between parents in the possession of these soft skills.

Third, financial resources available to the family enable parents to ensure a stimulating learning environment in terms of equipment and extra tuition (Bray 2020; Schneider, Hastings and LaBriola 2018; Zwier, Geven and van de Werfhorst 2021). While certain parents invest in supplementary tuition, 
to improve their offspring's educational outcomes, others are not able to do so. For that reason, differences in financial resources also underlie IEO. ${ }^{2}$

Insights into the relative importance of these three forms of family resources are crucial to develop policy interventions that might reduce IEO. Each of the previously mentioned mechanisms is likely connected with a different set of interventions. If the intergenerational transmission of key skills is the dominant mechanism, an effective intervention should aim at stimulating the acquisition of such skills in early childhood (Cunha and Heckman 2007; Cunha, Heckman and Schennach 2010) or in primary education, specifically aiming at disadvantaged youth. An example of such an intervention is High Dosage Tutoring (HDT) stimulating language and math skills (De Ree et al. 2021; Fryer and HowardNoveck 2020). However, if soft skills such as familiarity with the culture at school and knowledge about the educational system are more prominent in the intergenerational transmission of education, effective interventions are likely aimed at increasing parental engagement and involvement (Kim and Hill 2015; Sénéchal and Young 2008). Finally, when financial resources play a dominant role in IEO, governments could make learning equipment, free extra tuition or grants available for disadvantaged children (Bloome, Dyer and Zhou 2018).

Researchers have been able to identify the role of financial resources in the intergenerational transmission of education relative to the other two mechanisms due to the easy accessibility of data on family income and wealth. In general, the results point to a significant albeit modest contribution (De Graaf 1986; Huang 2013). However, little is known about the relative importance of either key skills or soft skills in the intergenerational transmission of education. This lacuna in stratification research is mainly due to data limitations as most studies simply lack comparable data on key skills or soft skills of parents and their offspring. Instead, these two mechanisms are usually proxied by the same variable, the effect of highest education of the parents, while controlling for financial resources. The key contribution of this study is that we include measures of school-related knowledge in the key domains of math and language for both generations as well as indicators for educational attainment and household income, allowing us to differentiate between the different mechanisms. We developed a unique and unparalleled dataset, the Intergenerational Transmission of Skills (ITS) dataset, covering more than 25,000 parents and their children from the Netherlands, including parent's and children's key skills measured at the same age using a similar test. ${ }^{3}$ This test is highly predictive for educational success (Feron, Schils and ter Weel 2016; Lek 2020). Using these data, we can estimate the relative importance

\footnotetext{
${ }^{2}$ In the paper, we also look at a fourth resource that may underlie IEO: the social capital of the family. In particular, we look at the education of the grandparents. However, measuring the effect of social capital is not the central aim of this paper.

${ }^{3}$ The current paper is one of two inaugural papers of the ITS project. The companion paper is an economic analysis by Hanushek et al. (2021). That paper focuses on identifying the causal impact of parental skills on children's skills.
} 
of the intergenerational transmission of key skills in IEO and relate this to the relative importance of soft skills and financial resources.

\section{Theoretical Framework}

\section{Family resources}

In the so-called 'family resource theory', Farkas (2003) distinguished three types of resources contributing to IEO. First, families differ in the financial resources they invest in the development of the human capital of their children. Second, families differ in the possession of cultural capital. This cultural capital does not just refer to participation in highbrow culture but is meant to include all competences parents have available to support and assist their child in education. The third type of family resource is the availability of social capital. Social networks of the family can cater for additional resources that determine school success. All these resources can partly explain IEO. Below we first elaborate on the financial and social capital perspectives. The role of financial resources is taken up in our main analysis, distinguishing the contribution of parent's key skills, parent's soft skills and parent's financial resources in IEO. The social capital perspective is taken up in an additional analysis but is not regarded as the main contribution of this paper. After discussing these two resources, we will have a longer exposé on the role of cultural capital, which we define as composed of parent's key skills and parent's soft skills.

\section{Financial resources}

Parents differ in the investments they make in the educational careers of their children (Farkas 2003; Schneider et al. 2018). The availability of financial resources in the family provides material stimuli for children's learning processes, in the form of learning equipment (laptop, study place), or pay for extra tuition. While financial resources used not to be stressed as the most important mechanism (De Graaf 1986; Huang 2013), recent developments in education, such as the rise in shadow education (Bray 2011) and increase in tuition fees (OECD 2020), bring renewed attention to this area (Bray 2020). Research shows that the participation in so-called 'shadow education', i.e., extra out-of-school educational activities to improve one's school performance, increases strongly all over the world (Bray 2011; Mori and Baker 2010). Children from lower social strata participate less in shadow education than children from higher strata, and this relationship between social origin and participation in shadow education is stronger in countries with high-stakes tests, such as the Netherlands (Zwier et al. 2021).

\section{Social capital}

Coleman (1988) introduced the concept of social capital to show the importance of social networks both within and outside the family to foster educational success. Since then, the importance of the extended family has been shown in several research (e.g., Adermon, Lindahl and Palme 2021; Jaeger 2012; Lehti, 
Erola and Tanskanen 2019; Modin, Erikson and Vågerö 2013; Moreno 2021). However, the findings are not always conclusive (for a review see Anderson, Sheppard and Monden) and some researchers have contested these findings pointing at the omitted variable bias for parental characteristics. Using the 1970 British Cohort Study, Klein and Kühhirt (2021) show that the direct effect of grandparent's education on grandchildren's verbal and numerical ability is small and statistically nonsignificant. In this paper, we will look at the effect of grandparents' education on grandchildren's skills in an additional analysis to see whether grandparent's education has an effect over and above the effect of parent's key skills, parent's soft skills and parent's financial resources.

\section{Cultural capital}

The concept cultural capital dates to the work of French sociologist Pierre Bourdieu (Bourdieu and Passeron 1977; Bourdieu 1984). According to Bourdieu (1985), cultural capital should be "seen as one of several resources (along with social, economic and symbolic capital) in which individuals invest, and which can be converted into one another to maximize one's upward mobility" (724). Although cultural capital played a dominant role in existing research on IEO, (e.g., Davies and Rizk 2018; DiMaggio 1982; Lareau and Weininger 2003), the concept itself proved to be inherently vague. This resulted in different definitions ranging from participation in and knowledge of 'highbrow' culture (e.g., DiMaggio 1982), to broader definitions such as the one proposed by Lamont and Lareau (1988): "institutionalized, i.e., widely shared, high status cultural signals (attitudes, preferences, formal knowledge, behaviors, goals, and credentials) used for social and cultural exclusion" (Lamont and Lareau 1988:156). The vagueness of the concept led Kingston (2001) to publish a critical review with the provoking title 'Unfulfilled Promise Of Cultural Capital Theory' in which he makes two arguments. First, he stated that cultural capital, defined narrowly as being member of an exclusive cultural group, did not fulfill the expectation that it significantly explains the relation between social class and school success. Second, due to the various operationalizations of the concept, cultural capital did become a catch-all term. He strongly advocated to focus more directly on specific school-related resources that affect academic success. For example, if basic reading skills are the main driver of school success, one should call it as it is, and "recognize that the modifier "cultural" before "resources" almost inevitably introduces constructionist connotations of arbitrariness (i.e., books = Mahler)" (Kingston 2001:95). We follow this critique by avoiding the term cultural capital and instead focusing on two important underlying composites: parental key skills (e.g., proficiency in school-related subjects such as math and language), and parental 'soft' skills (e.g., knowing how to manoeuvre well in education, familiarity with the school culture and positive attitude towards learning).

Key skills, cognitive ability, and soft skills

Farkas (2003) also regarded the role of key skills as part of a range of activities that affect school success ranging from parental assistance in homework to participation in highbrow culture. The following quote 
illustrates his point: "Lying between these two extremes are the more basic literacy and mathematics skills and habits that are correlated with parental social class, transmitted from parents to children, valued by teachers, and lead to real productivity increases in the worlds of school and work." (Farkas 2003:546). Note that the part of the quote relating to 'real productivity increases' fits well with the economic and sociological literature highlighting the role of key skills in determining success in education and work (Hanushek et al. 2015; Van der Velden and Bijlsma 2019).

Key skills can be defined as "cognitive skills in key domains relevant for success in education". The focus on key skills was prompted by a shift in attention in international research from the role of educational attainment to a more precise measurement of human capital, namely key informationprocessing skills (Hanushek and Woessmann 2011) or key skills in short. This focus on key skills was amplified by the introduction of international large-scale assessments, such as OECD's Programme for International Student Assessment (PISA), Programme for the International Assessment of Adult Competencies (PIAAC), and the IEA studies Progress in International Reading Literacy Study (PIRLS), and The Trends in International Mathematics and Science Study (TIMMS). Common to all these assessments is that they include numeracy and literacy (next to other domains such as science or problem-solving).

The concept of numeracy is defined as "the ability to access, use, interpret and communicate mathematical information and ideas in order to engage in and manage the mathematical demands of a range of situations in adult life" (OECD 2013:20). Literacy is defined as "the ability to understand, evaluate, use and engage with written texts to participate in society, to achieve one's goals, and to develop one's knowledge and potential. It encompasses a range of skills from the decoding of written words and sentences to the comprehension, interpretation, and evaluation of complex texts" (OECD 2013:20). It is important to stress that these key skills are not simply equivalent to innate cognitive ability or intelligence. Of course, innate cognitive ability is an important basis to develop such skills, but if this potential is not developed, the actual skills that people have will not result in higher productivity (whether in education or at work).

There is strong evidence that at the individual level, literacy and numeracy are highly predictive in terms of educational attainment (e.g., Fischbach et al. 2013; Knighton and Bussière 2006) and labor market success (e.g., Hanushek et al. 2015; Levels, van der Velden and Allen 2014; McIntosh and Vignoles 2001), and even affect non-economic outcomes such as health and social engagement (e.g., Borgonovi, Pokropek and Rosenbloom 2016; Kakarmath et al. 2018; Martin 2018; Vera-Toscano, Rodrigues and Costa 2017).

Soft skills are defined here as "skills - other than key skills - that are relevant for success in education". One relevant soft skill is knowledge how the education system works. It is important that parents understand how the education system is organized, what the important decision moments are, and what 
the short- and long-term consequences of certain choices are. Using Dutch panel data, Forster and Van de Werfhorst (2020) show that parents' knowledge is a significant predictor of educational success of their children net of parents' education and other socio-demographic characteristics. Another important type of soft skills are attitudes that foster a successful educational career, such as perseverance, grit, achievement-motivation, or curiosity (for an overview see Borghans et al. 2008). Duckworth and Seligman (2005) for example report on the importance of self-discipline in predicting academic performance. These attitudes play an important role as they can amplify the role of key skills (making the impact of key skills more relevant for educational success), as was already argued in the early 60's by the Canadian psychologist Vroom (Vroom 1964). A third relevant type of soft skill is familiarity with the school's culture (i.e., an alignment between the culture at home and the culture at school). For example, Calarco (2014) showed that middle- and working-class parents expressed contrasting beliefs about what is appropriate classroom behavior, beliefs that shaped parents' coaching of their children. This coaching affected children's behavior and problem-solving strategies in class.

\section{Earlier research on intergenerational transmission of key skills}

Although the intergenerational transmission of key skills is regarded as one of the central mechanisms in IEO, there is little empirical research that substantiates this. This is mainly because skills measures covering both parent's and offspring's generations are scarce. One line of research looks at the intergenerational skill transmission of intelligence, showing correlates between 0.20 and 0.50 (Anger and Heineck 2010; Anger 2012; Björklund, Hederos Eriksson and Jäntti 2010; Black, Devereux and Salvanes 2009). Related to this are the twin and adoptee studies that try to unravel the genetic and environmental components of cognitive ability (Adermon et al. 2021; Black and Devereux 2011; Hart, Little and van Bergen 2021; Sacerdote 2011). These designs take advantage of twin or adoptee samples that differ in genetic relatedness, meaning identical twins versus not-identical twins, or differ in environmental exposure, meaning studies that look at adoptees or sometimes even twin adoptees. Although these studies show strong intergenerational effects, we like to stress that they all focus on intelligence rather than the type of key skills as we defined it. A third related line of research are studies on educational success of siblings. Dating back to the late 80s (e.g., Hauser and Wong 1989), researchers used resemblance in test scores or educational success of siblings to assess the strength of the family (Grätz et al. 2021; Marks and Mooi-Reci 2016; Nicoletti and Rabe 2019). Although these studies focus on key skills rather than intelligence, they lack comparable skills of the parents to show the intergenerational transmission of such skills. The few studies that do have skills measures of parents and children (Tzanakis 2011), often deploy measures at different ages, which is highly problematic.

As far as we know, there are only two exceptions. Brown, McIntosh and Taylor (2011) exploit an additional wave in the British National Child Development Study (NCDS) that includes a random sample of the NCDS original respondents' offspring. The parents were tested at age 7 in reading and 
arithmetic. All children of a random group of one third of the NCDS respondents were tested in 1991, when the parents were aged 33, and the children were aged five up to the age of 18 . The researchers study the intergenerational transmission of these test scores with an instrumental variable (IV) approach, exploiting regional differences at the age parents first went to formal education. They find evidence for a strong intergenerational transmission of reading skills that is not explained by genetic differences. For math skills, they do not find such an effect in the IV analysis, suggesting that the intergenerational transmission of math skills is more genetic (Brown et al. 2011). A related study is carried out by De Coulon, Meschi and Vignoles (2011) who use multiple waves of the British Cohort Study (BCS) that started in the seventies. As the level of skills is not static over the life course, the parental skills are measured at two points in time, i.e., at age five and at age 34. The cognitive skills of the offspring are measured between ages three and five with an ability test including a verbal and numeric part. De Coulon et al. (2011) show that the correlation between the parent's childhood cognitive skills and their children's cognitive skills measured at age five is around .20. After including the parental cognitive skills at age 34, this correlation decreases to around .10.

Although both studies shed a first light on the intergenerational transmission of key skills, they have severe limitations. The most important limitations are that the tests used for the children seem to capture general cognitive ability, rather than school-related knowledge on math and reading, and that the tests used are not the same for the parents and children. Another serious issue is selectivity of the data. In the paper by De Coulon et al. (2011), children were tested at ages three to five, when their parents were 34 . This means that parents at the tails of the skills distribution are underrepresented as they usually have children at a younger age (low-skilled parents) or older age (high-skilled parents). For the Brown et al. (2011) study, this issue is even more pronounced as the children who were tested range in age from five to 18. The oldest children in the sample are thus offspring from very young parents, while for the youngest children the highly educated parents are overrepresented. This selectivity in the study sample of both papers may have seriously affected the outcomes.

\section{Contribution of our study}

In line with the 'family resource theory', we estimate a structural model in which we include multiple important family resources, i.e., financial resources (measured by household income), parent's key skills (measured as their proficiency at age 12 in math and language), and parent's soft skills (measured indirectly as the residual effects of parent's education, after controlling for parent's key skills and the family's financial resources). We will use high-quality register data to identify the household income in the period short before children took the test. Regarding key skills, our study overcomes the limitations of previous studies by using a unique dataset that links a standardized test in math and language made by the parents when they were 12 years old, to the same test that was taken by their children when they were at the same age. This test is used in the Netherlands to determine track 
allocation in secondary education and comes closer to measuring key skills relevant for success in education than the tests used in the above-mentioned studies. We use these tests to identify the intergenerational transmission of key skills. In a robustness check, we additionally control for parental differences in IQ to show that the intergenerational transmission of key skills is not solely driven by parental differences in intelligence.

\section{Study context: the Dutch education system}

Before describing our data, it is important to understand some key features of the Dutch educational system relevant for our data. The Dutch education system is a so-called early stratifying system (Bol and van de Werfhorst 2013), where students are allocated to different tracks in secondary education after the final year of primary education (grade 6, at age 12). The allocation is based on two factors: the performance of students on a national test, the so-called CITO-test (Central Institute for Test Development (CITO)), and the advice of the primary school teacher. The CITO-test is a high-stakes test measuring school performance in math and Dutch language. Although the tests are annually updated and occasionally cover other domains as well, the core principle behind the test and its aims have not changed over the years, namely, to give an objective indication of the student's performance in the key domains of language and math. These domains are considered crucial for successful completion of secondary education. It is important to note that the use of a national test was not mandatory before school year 2014/15, but since the introduction of the CITO-test in 1970 a large majority (around 85\%) of the schools in primary education have used them. The second factor is the primary school teacher's advice. This advice is partly based on the results of the previously mentioned national test and partly based on the teacher's expectation of whether the student will succeed in secondary education at the advised level.

\section{Data and measurement}

Data

For this paper we have developed a unique and unparalleled data source: the ITS dataset. The ITS dataset is a combination of panel survey data gathered in the 1970s and 1980s complemented with register data available at Statistics Netherlands. The panel data consist of three cohorts that started in secondary education in 1977, $1983^{4}$ and 1989 respectively. Each of these longitudinal surveys are nationally representative panels of 37,280 (1977), 16,813 (1983) and 19,524 (1989) students entering

Dutch secondary education (grade 7 , age 13). The surveys were carried out using a two-stage sampling

\footnotetext{
${ }^{4}$ In fact, the 1983 cohort started in 1982 in the final year of primary education. From this cohort we selected those respondents that were in secondary education in the following school year, so that all three cohorts have the same characteristics in terms of sample design. We therefore refer to this cohort as the 1983 cohort. Results do not change if we keep the full original 1982 cohort (see Table S1 in Supplementary Material).
} 
design: first a random sample of schools was drawn, and then classes within these schools (for more information, see Jacobs, Vermeulen and Van der Velden 2021a).

Each cohort started at the beginning of the school year with an assessment of the language and math skills, using a short version of the above-mentioned CITO-test. Questionnaires were also sent to their parents to gather basic background information. All students were subsequently followed during their school career, assessing their position in education (i.e., track and grade) annually until they left education.

For most of the students in the original cohorts, basic identifying information such as name and address at the time of the survey, allowed us to link these cohort data to register data from Statistics Netherlands. For the latest cohort we could rely on a unique personal identifier which made the linking process successful in $98 \%$ of the cases. For the other cohorts, the percentage of original students that could be linked to the register is lower, namely $81 \%$ (1977 cohort) and 88\% (1983 cohort).

In the first two decades of the new millennium, the original students from the three cohorts were in their 30 s or 40 s, the age at which they could have had children themselves that would enter secondary education. Statistics Netherlands has register data of all schools that participated in the CITO-test from school year 2005/2006 onwards. As indicated earlier, this CITO-test is taken in the final year (grade 6) of primary education. We linked the original cohort data to the register data of their children, including test scores as well as other information on children's educational career. The latter information is available in the so-called Netherlands Cohort Study on Education (NCO) in which multiple sources of register data on education are linked (for an overview, see Haelermans et al. 2020).

The ITS dataset currently contains 25,287 unique parents with in total 41,326 unique children. Table 1 provides an overview (see Jacobs et al. (2021a) and Appendix A for a detailed description of the original cohorts and the linkage process). ${ }^{5}$

\footnotetext{
${ }^{5}$ Note that the total number of parents at the bottom of the table is slightly higher than the number of observations in the descriptive Table 2 and the subsequent analyses. This is because, some parents in the original cohorts married or cohabitated and got children. If both parents were included in the education cohorts, we randomly selected one of them.
} 
Table 1. Overview combining all data

\begin{tabular}{llll}
\hline & $\begin{array}{l}\text { Education } \\
\text { cohort 1977 }\end{array}$ & $\begin{array}{l}\text { Education } \\
\text { cohort 1983 }\end{array}$ & $\begin{array}{l}\text { Education } \\
\text { cohort 1989 }\end{array}$ \\
\hline A. Original file & 37,280 & 16,813 & 19,524 \\
\hline $\begin{array}{l}\text { B. Respondents with ID that can } \\
\text { be linked }\end{array}$ & $\begin{array}{l}30,171 \\
(81 \% \text { of A) }\end{array}$ & $\begin{array}{l}14,764 \\
(88 \% \text { of A) }\end{array}$ & $\begin{array}{l}19,111 \\
(98 \% \text { of A) }\end{array}$ \\
\hline C. Respondents with test data & $\begin{array}{l}25,462 \\
(69 \% \text { of A) }\end{array}$ & $\begin{array}{l}14,613 \\
(87 \% \text { of A) }\end{array}$ & $\begin{array}{l}18,015 \\
(92 \% \text { of A) }\end{array}$ \\
\hline D. Respondents with children & $\begin{array}{l}19,633 \text { parents } \\
(53 \% \text { of A) }\end{array}$ & $\begin{array}{l}11,315 \text { parents } \\
(67 \% \text { of A) }\end{array}$ & $\begin{array}{l}13,657 \text { parents } \\
(70 \% \text { of A) }\end{array}$ \\
& 42,616 children & 24,330 children & 29,089 children \\
\hline E. Children with test data & $\begin{array}{l}13,248 \text { parents } \\
(36 \% \text { of A) }\end{array}$ & $\begin{array}{l}7,649 \text { parents } \\
(46 \% \text { of A) }\end{array}$ & $\begin{array}{l}4,586 \text { parents } \\
(24 \% \text { of A) }\end{array}$ \\
& 22,241 children \\
12,872 children & 6,361 children \\
& $(52 \%$ of D) & $(53 \%$ of D) & $(22 \%$ of D) \\
& & &
\end{tabular}

As explained earlier, sample sizes vary across cohorts, mainly due to differences in original sample sizes and differences in the possibility to link original respondents to register data. On top of that, we have missing information on the test data of parents, specifically in the 1977 cohort $(\mathrm{N}=4,709)$. These parents were also left out of the subsequent analyses. Furthermore, we have differences across the cohorts in the number of children we can observe in our 2006-2019 observation window. Although most parents in all three cohorts have children in our observation window ${ }^{6}$, we only have test data for children in respectively 52\% (cohort 1977), 53\% (cohort 1983) and 22\% (cohort 1989) of the cases. In the case of multiple children for which test data were available, we randomly chose one thus avoiding our model estimations from becoming too demanding.

\section{Measurements}

Key skills

The short version of the CITO-test consisted of 25 math items and 45 language items in cohort 1977 and 20 items for each domain in cohorts 1983 and 1989. The test results are standardized for each domain-cohort combination separately using the complete original data set. ${ }^{7}$

The CITO-test data of the children is available from school year 2005/2006 to 2018/2019 (in the school year 2019/2020 no test was taken due to COVID-19). Depending on the year, the test consists of 60 to

\footnotetext{
${ }^{6}$ The percentage of parents with children in the 1977 cohort is lower as household information is only available from 1995 onwards. This means that the children who left the household before 1995 are not observed.

${ }^{7}$ A possible problem is that the cohorts are grade cohorts rather than age cohorts. This means that while most respondents were 13 at the time of test, some were older due to grade repetition in primary education, and some are younger due to acceleration. We did additional analyses using test scores corrected for these age differences. This proved not to affect the estimates in the main model (see Table S2 in Supplementary Material).
} 
85 math items and 100 to 135 language items. The test results are standardized for each domain-test year combination using the complete original data sets. As of school year 2014/2015 other test suppliers entered the market. Because schools that switched to a different test supplier might be selective on population characteristics (Jacobs, van der Velden and van Vugt 2021b), the standardization is done based on the schools that participated in the CITO test every year.

We use the language and math scores separately to construct measures for key skills.

\section{Education variables}

Parent's and grandparents' education was monitored by Statistics Netherlands using a detailed coding scheme. These categories are converted into years of schooling using the so-called educational ladder by Bosker and Velden (1989). For the children, we measure the initial track in secondary education converted to years of schooling. When a child starts in secondary education in a mixed track, we use the first time the child is observed in a single track to determine the initial track. For the children who are not yet in a single track, because they are still in a mixed track in secondary education, we use the average years of schooling of the tracks they still have direct access to, given the mixed track they are in.

\section{Financial resources}

We use household income for the operationalization of financial resources. Household income is measured as the average standardized disposable private household income in percentiles in the period one to three years before the child took the CITO-test ${ }^{8}$. The disposable income of the household consists of the gross income excluding transfer payments, such as alimony, income insurance contributions, health insurance premiums, and taxes on income and assets. The measure is adjusted for the size and composition of households.

\section{Intelligence}

In the original cohorts, the parents also took a non-verbal intelligences test: the TIB test for the 1977 cohort and the PSB-3 test for the other two cohorts. The test scores were standardized within each cohort using the full cohort.

\section{Other skills}

As previously mentioned, the teacher's advice is partly based on the results of the pupils on the CITOtest and partly based on teacher's expectation whether the pupil will succeed in secondary education.

\footnotetext{
${ }^{8} \mathrm{We}$ look at the period one to three years for household income, because the household income of self-employed fluctuates considerably on a yearly basis.
} 
This teacher's advice is available for both parents and their children. We use a regression analysis to calculate other non-measured skills defined as the residual in the teacher's advice after controlling for student's test performance.

Table 2 displays the descriptive statistics of the main variables in our analyses, separately for the three cohorts and for the total sample. 
Table 2. Descriptive statistics

\begin{tabular}{|c|c|c|c|c|c|c|c|c|c|c|c|c|}
\hline & \multicolumn{3}{|c|}{ Education cohort 1977} & \multicolumn{3}{|c|}{ Education cohort 1983} & \multicolumn{3}{|c|}{ Education cohort 1989} & \multicolumn{3}{|c|}{ All education cohorts } \\
\hline & $\mathrm{N}$ & Mean & Std. Dev. & $\mathrm{N}$ & Mean & Std. Dev. & $\mathrm{N}$ & Mean & Std. Dev. & $\mathrm{N}$ & Mean & Std. Dev. \\
\hline \multicolumn{13}{|l|}{ Child } \\
\hline Math skills child (std) & 13,184 & 0,065 & 0,964 & 7,563 & $-0,032$ & 0,983 & 4,540 & $-0,146$ & 1,003 & 25,287 & $-0,002$ & 0,980 \\
\hline Language skills child (std) & 13,184 & 0,098 & 0,940 & 7,563 & $-0,013$ & 0,974 & 4,540 & $-0,146$ & 1,004 & 25,287 & 0,021 & 0,966 \\
\hline $\begin{array}{l}\text { Initial track in secondary education in } \\
\text { years }\end{array}$ & 13,122 & 4,66 & 1,181 & 7,503 & 4,50 & 1,226 & 4,490 & 4,33 & 1,222 & 25,115 & 4,55 & 1,209 \\
\hline Female child & 13,184 & 0,499 & 0,500 & 7,563 & 0,507 & 0,500 & 4,540 & 0,510 & 0,500 & 25,287 & 0,504 & 0,500 \\
\hline Other skills (std) & 11,045 & 0,084 & 0,961 & 7,135 & 0,012 & 0,967 & 4,463 & $-0,071$ & 1,027 & 22,643 & 0,031 & 0,978 \\
\hline \multicolumn{13}{|l|}{ Parent } \\
\hline Math skills parent (std) & 13,184 & 0,157 & 0,971 & 7,563 & $-0,010$ & 0,986 & 4,540 & $-0,164$ & 0,963 & 25,287 & 0,049 & 0,981 \\
\hline Language skills parent (std) & 13,184 & 0,146 & 0,948 & 7,563 & 0,008 & 0,986 & 4,540 & $-0,096$ & 0,973 & 25,287 & 0,061 & 0,969 \\
\hline Education in years & 13,162 & 10,80 & 2,915 & 7,080 & 10,71 & 2,979 & 4,098 & 10,16 & 2,851 & 24,340 & 10,67 & 2,932 \\
\hline Low education (dummy) & 13,162 & 0,270 & 0,444 & 7,080 & 0,311 & 0,463 & 4,098 & 0,367 & 0,482 & 24,340 & 0,298 & 0,457 \\
\hline Female parent & 13,184 & 0,496 & 0,500 & 7,563 & 0,559 & 0,497 & 4,540 & 0,616 & 0,486 & 25,287 & 0,537 & 0,499 \\
\hline IQ scores (std) & 7,539 & 0,139 & 0,956 & 7,537 & 0,014 & 0,990 & 4,540 & $-0,131$ & 0,607 & 19,616 & 0,028 & 0,908 \\
\hline Other skills (std) & 12,754 & 0,045 & 1,004 & 7,465 & $-0,005$ & 0,992 & 4,392 & $-0,053$ & 0,990 & 24,611 & 0,012 & 0,998 \\
\hline Household income (in percentiles) & 13,050 & 57,260 & 24,437 & 7,499 & 54,568 & 24,665 & 4,494 & 47,481 & 23,699 & 25,043 & 54,699 & 24,635 \\
\hline Low household income (dummy) & 13,050 & 0,385 & 0,487 & 7,499 & 0,434 & 0,496 & 4,494 & 0,548 & 0,498 & 25,043 & 0,429 & 0,495 \\
\hline Education grandmother in years & 12,050 & 7,30 & 2,710 & 6,751 & 7,21 & 2,654 & 4,189 & 7,95 & 2,702 & 22,990 & 7,395 & 2,706 \\
\hline Education grandfather in years & 12,447 & 9,02 & 3,388 & 6,500 & 7,92 & 3,304 & 3,968 & 8,97 & 3,236 & 22,915 & 8,702 & 3,375 \\
\hline
\end{tabular}

Source: ITS dataset 
Table 2 reflects the earlier differences in number of observations for the different cohorts (see Table 1). Moreover, we also observe lacking information on some of the key variables, such as initial track in education for the children, IQ scores of the parents, highest level of education of the parents or household income. Note, however, that the percentage of missing information is relatively low, and that all missing information is automatically imputed in the structural equation models. ${ }^{9}$

Although we standardized math and language skills for both parents and children for each cohort/year separately using the original cohorts, we observe in Table 2 that the means of these skills are slightly above average for cohort 1977 and below average for cohort 1989. This reflects the fact that for cohort 1977 we mainly observe older parents, who are more likely to be higher educated, while in cohort 1989 we mainly observe younger parents, and these are more likely to be lower educated. However, the distributions of the math and language skills for the 1983 cohort and for the combined cohorts are close to normal. This should give confidence in our main analysis in which we work with the combined cohorts. ${ }^{10}$

\section{Method}

To assess to the relative contribution to IEO of the three types of resources available to the family (parent's financial resources, parent's key skills, and parent's soft skills), an extended version of the classical status attainment model (Blau and Duncan 1967) is estimated using structural equation modeling (SEM). The advantage of using SEM is that it can simultaneously include path models and measurement models. In path models complex models can be tested, while in measurement models unobserved constructs, i.e., latent variables, can be estimated with factor analysis. The inclusion of a measurement model thus enables us to correct for measurement errors in the skill tests (Ramlall 2017). These measurement errors would otherwise cause a downward bias in the observed relations.

We first estimate the intergenerational transmission of education by looking at the correlation between the parent's highest level of education and the offspring's initial track choice in secondary education. This model is compared to the intergenerational transmission of key skills. Here, measurement models for both parents and children are included to measure the latent construct 'key skills' with the observed math and language skills. In the structural model, the relation between the two latent variables is estimated. Next, we estimate a structural model with parent's education predicting, directly and indirectly via the child's key skills, the child's initial track choice. In this model, we also include the financial resources available in the family by looking at the effects of household income. In the final

\footnotetext{
${ }^{9}$ As a robustness check, we also ran all SEM models without imputation for missing data. Our main conclusions remain the same (see Table S3 in Supplementary Material).

${ }^{10}$ In a robustness check, we checked whether the results are substantially different if we analyse each cohort separately. That is not the case (see Table S4 in Supplementary Material).
} 
structural model, we also include the key skills of the parent, allowing us to differentiate between the three family resources.

All SEM models are estimated in Mplus 8.0 (Muthén and Muthén 2017) using "Maximum Likelihood estimation with robust standard errors" (MLR). The model fit is determined by looking at the Root Mean Square Error of Approximation (RMSEA), which needs to be below 0.05 to indicate a good fit (Steiger 1990), the Standardized Root Mean Square Residual (SRMR) which should be below 0.8, and the Tucker Lewis Index (TLI) and Comparative Fit Index (CFI) that should be above 0.95 (Bentler 1990).

\section{Main results}

The upper panel of Figure 1 shows the raw correlation between parent's highest level of schooling and their offspring's level of initial track in secondary education, both expressed in years of schooling.

Figure 1: The intergenerational transmission of education and skills compared
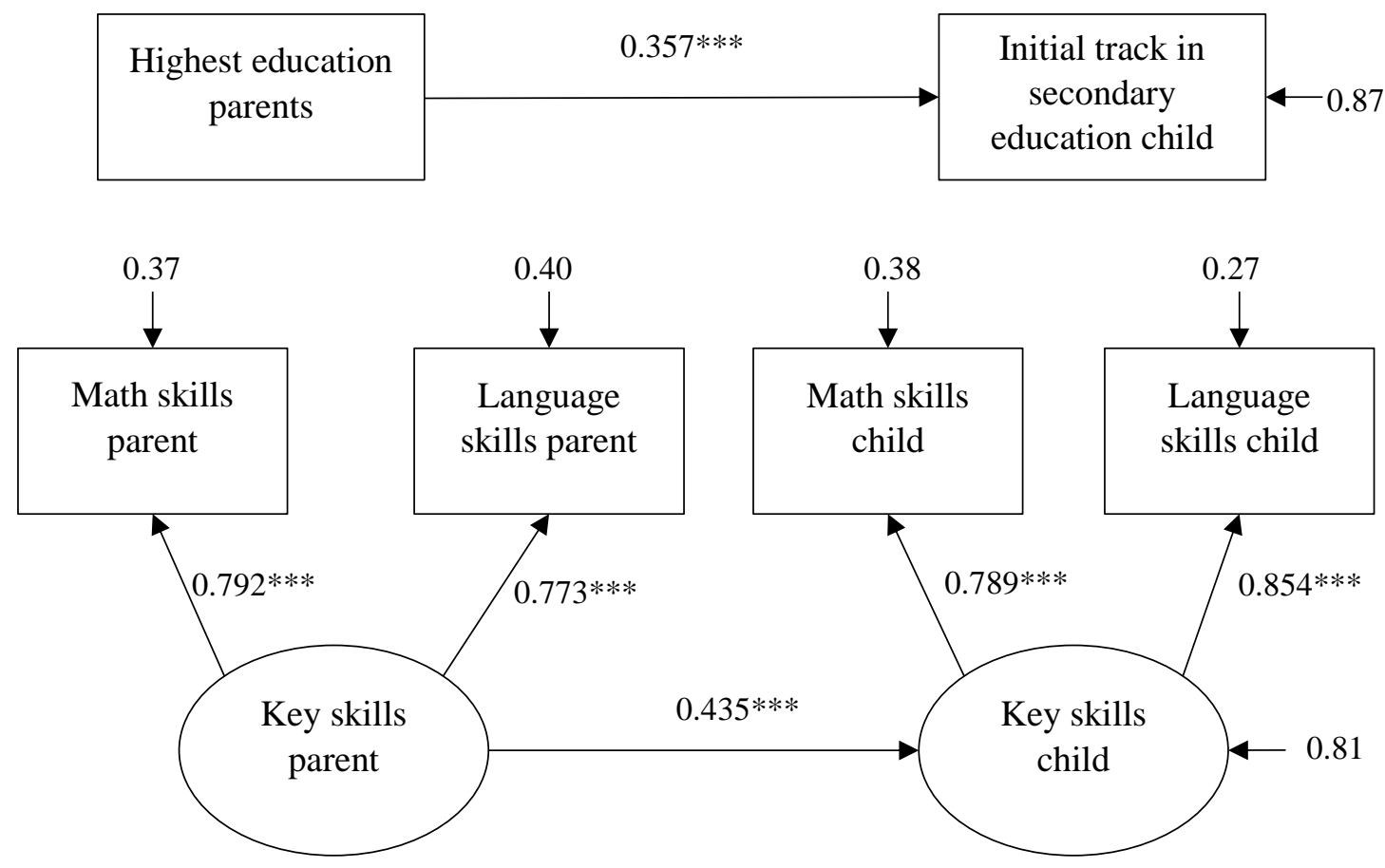

Source: ITS dataset. Standardized model coefficients are displayed; the standard errors are provided in Table S5 of the Supplementary Material.

$N_{\text {SEMmodel }}=25,275 ; R M S E A=0.000 ; C F I=1.000 ; T L I=1.000 ; S R M R=0.000$;

$N_{\text {SEMmodel } 2}=25,287 ; R M S E A=0.113 ; C F I=0.989 ; T L I=0.932 ; S R M R=0.0010$.

$* p<0.05 ; * * p<0.01 ; * * * p<0.001$ 
This correlation is 0.357 , indicating that one standard deviation increase in parent's level of education is associated with one third of a standard deviation increase in the initial track level of their offspring. This correlation is comparable to what is found in other countries (Adermon et al. 2021; Black, Devereux and Salvanes 2005). In the lower panel we observe the correlation between the latent constructs 'key skills parent' and 'key skills child'. ${ }^{11}$ We observe that the measurement model is quite satisfactory, with roughly similar and high factor loadings of both math and language. This means that the latent construct is picking up both types of skills. The parameter of interest is the effect of 'key skills parent' on 'key skills child'. Interestingly, with an estimate of 0.435 , this coefficient is even larger than the coefficient for the intergenerational transmission of education (0.357). This suggests that intergenerational transmission of skills is very strong and thus potentially an important underlying mechanism explaining IEO.

\footnotetext{
${ }^{11}$ The Modification Indices in the initial model suggested that the model fit could be further improved by allowing correlated error terms between the test scores of parents and children within the same domain. In a robustness check, we checked whether this affected the correlation. This was not the case (see Table S5 in Supplementary Material).
} 
Figure 2: The classical attainment model without parental skills

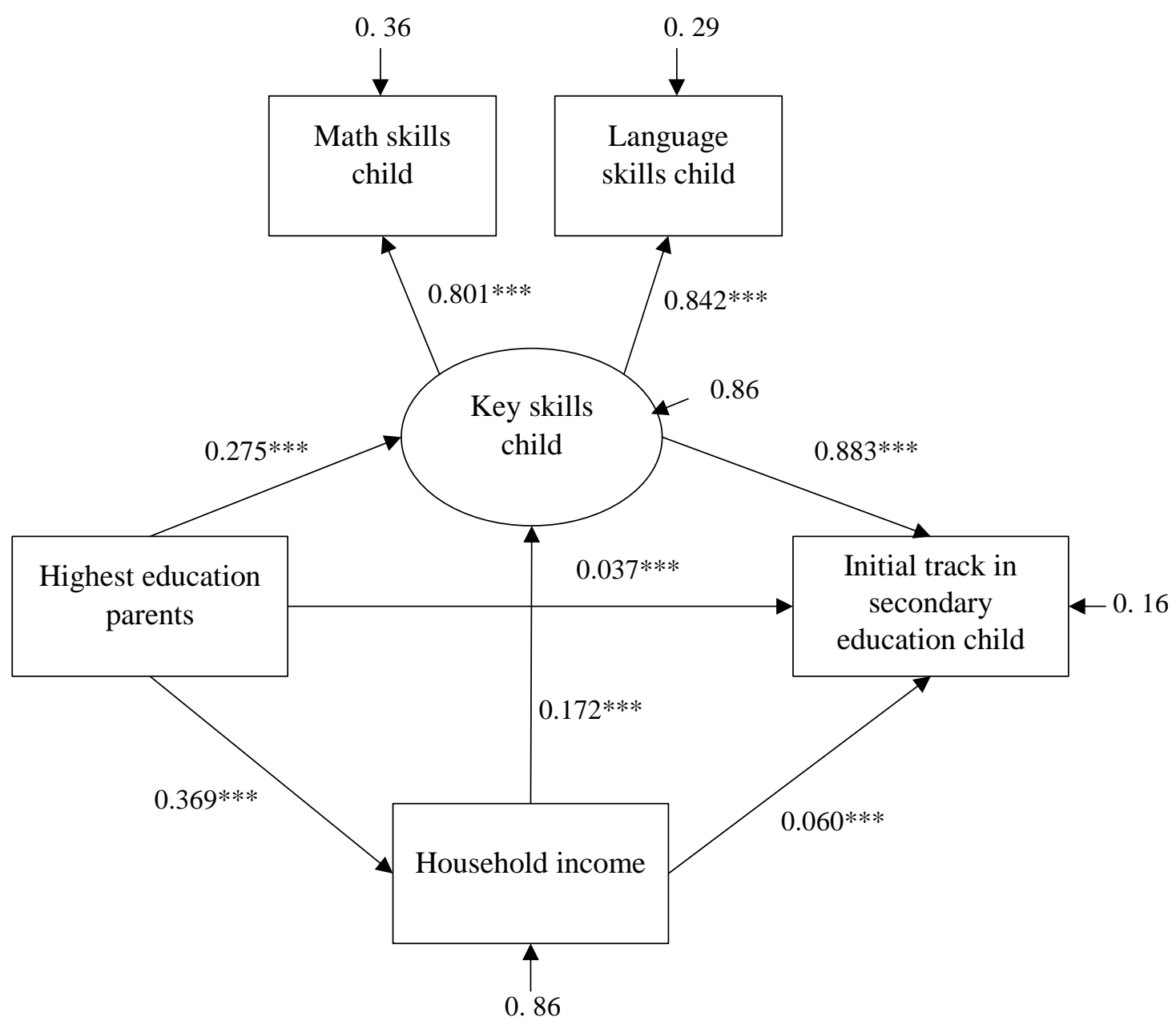

Source: ITS dataset; $N=25,287$; Standardized model coefficients are displayed; the standard errors are provided in Table S6 of the Supplementary Material. Model fit: RMSEA=0.014; CFI=1.000; TLI=0.999; $S R M R=0.002 ; * p<0.05 ; * * p<0.01 ; * * * p<0.001$

Figure 2 shows a classical attainment model in which we include parent's education, household income, children's key skills and children's choice of initial track. As we can see, initial track placement is largely determined by the children's key skills $(0.883)$. The parent's level of schooling has a strong effect on their offspring's skills of 0.275 . Household income has an additional effect on children's skills of 0.172. Still there are small, yet significant direct effects of parent's highest level of education and household income on children's initial track placement of 0.037 and 0.06 .

The key skills of children thus play a dominant role in the transition from primary to secondary education. As this transition is a key determinant in the educational success of children from loweducated parents, it is crucial to identify where this difference in key skills of children comes from. Is it related to the parent's key skills, is it related to parent's soft skills, or is it related to the financial resources available to the children? 
Figure 3: The three mechanisms underlying IEO: parent's key skills (proficiency in math and language), family's financial resources (household income) or parent's soft skills (remaining effects of parent's educational attainment after controlling for the other two)

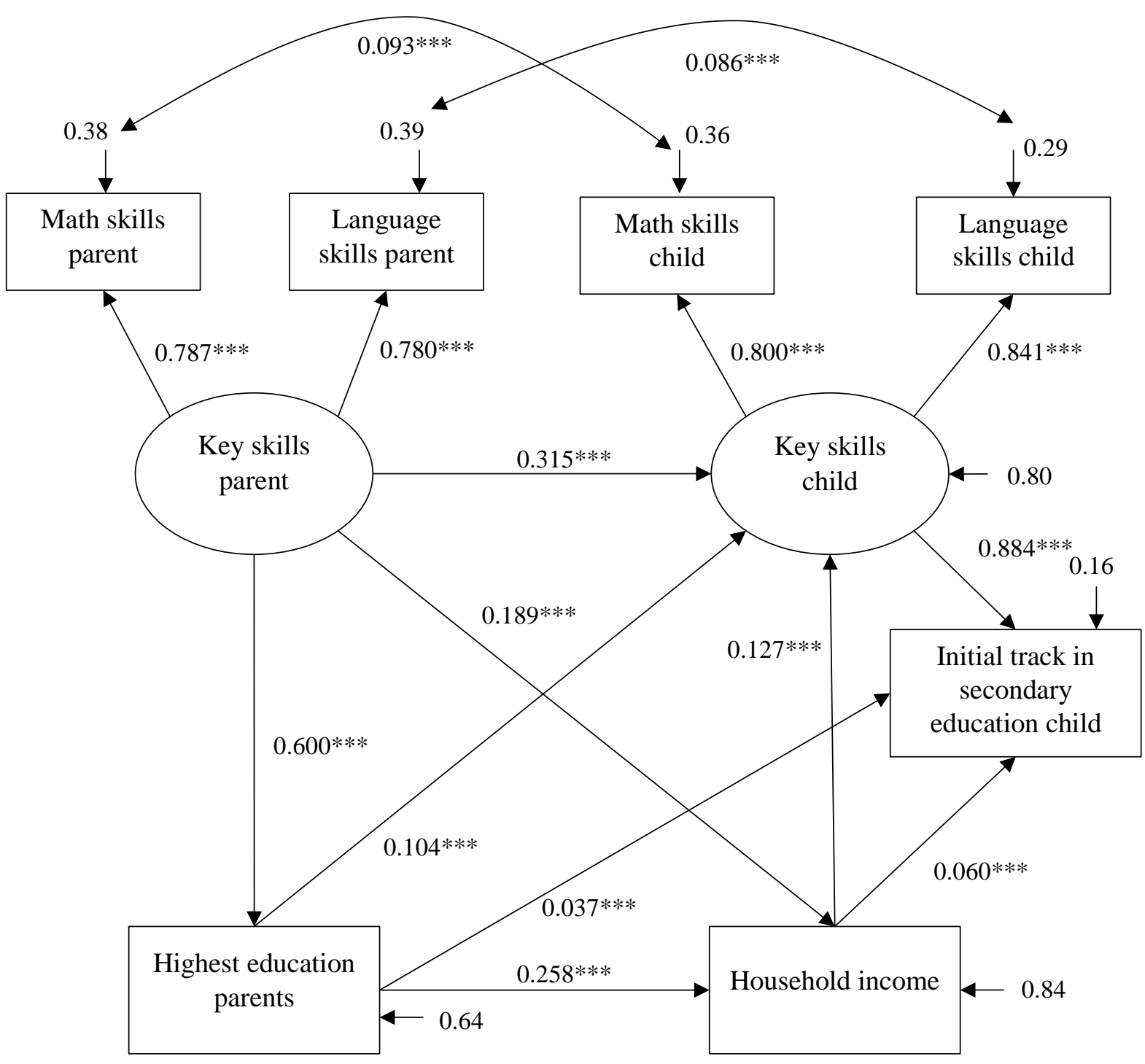

Source: ITS dataset; $N=25,287$; Standardized model coefficients are displayed; the standard errors are provided in Table $S 7$ of the Supplementary Material. RMSEA=0.019; CFI=0.999; TLI=0.997; SRMR=0.005; $* p<0.05 ; * * p<0.01 ; * * * p<0.001$

If we look at the model fit indicators, we see an overall good model fit (i.e., RMSEA $<0,05$; SRMR $<$ 0.08; CFI and TLI > 0.95). The specification in the initial model suggested that the model fit could be further improved by allowing correlated error terms between the test scores of parents and children within the same domain, which we did in the model shown above.

The introduction of parent's key skills (see Figure 3), change the estimates of the parameters shown in Figure 2. What has remained the same are the effect of children's key skills on initial track and the 
direct effects of parent's education and household income on their children's initial track choice. But the direct effect of parent's education on their children's key skills decreases substantially from 0.275 to 0.104 . The estimate of household income on the children's key skills also decreases, albeit less substantial, from 0.172 to 0.127 . Instead, we observe a strong direct effect of parent's key skills on their children's key skills of 0.315 . As we control for parent's key skills, the remaining effects of parent's education is interpreted as a proxy of parent's soft skills.

Table 3: Mechanisms affecting children's key skills and children's choice of initial track

\begin{tabular}{|l|l|l|l|l|}
\hline & $\begin{array}{l}\text { Direct effect } \\
\text { on key skills } \\
\text { child }\end{array}$ & $\%$ & $\begin{array}{l}\text { Direct and indirect (through key } \\
\text { skills child) effect on initial track } \\
\text { in secondary education }\end{array}$ & $\%$ \\
\hline Mechanism & & & & \\
\hline Parent's key skills & 0.315 & $57.7 \%$ & 0.278 & \\
\hline Parent's soft skills & 0.104 & $19.0 \%$ & 0.129 & $48.0 \%$ \\
\hline Financial resources & 0.127 & $23.3 \%$ & 0.172 & $22.3 \%$ \\
\hline Total effect & 0.546 & $100.0 \%$ & 0.579 & $100 \%$ \\
\hline $\begin{array}{l}\text { Indirect effect of } \\
\text { parent's key skills } \\
\text { (through education } \\
\text { or financial } \\
\text { resources) }\end{array}$ & 0.106 & & 0.136 & \\
\hline Souce: & & & & \\
\hline
\end{tabular}

Source: ITS dataset; $N=25,287$; Note: Standardized model coefficients are displayed

Table 3 summarizes the relative importance of the main mechanisms that drive IEO based on the estimates from Figure 3. If we focus on the key skills of the children first, we can observe that the largest effect comes from the parent's key skills. This effect accounts for $57.7 \%$ of the total effect of resources available in the family. The financial resources take up $23.3 \%$ and parent's soft skills the remaining $19 \%$. If we look at the total effects of these resources on children's allocation to the initial track in secondary education, the relative importance of financial resources and parent's soft skills increase somewhat to $29.7 \%$ and $22.3 \%$ respectively. We can thus conclude that parent's key skills are the main mechanism driving IEO, although the role of financial resources and parent's soft skills should not be underestimated: together these two types of resources are just as important as the key skills of the parents.

The key skills of the parents (expressed as the proficiency in math and language) thus explain a large part of IEO. In a way, the relative importance of this form of family resource is even underestimated as parent's key skills also affect the acquisition of their soft skills and financial resources, which in turn affect the school success of their offspring. Compared to the direct effect of parent's key skills, this indirect effect is much smaller but still important, with a total indirect effect ${ }^{12}$ size of 0.106 (compared

12 These total indirect effects are estimated using bootstrapping in Mplus. 
to the direct effect of 0,315). Similarly, the indirect effect on children's initial track is 0.136 (compared to 0.278 ). This implies that parent's key skills also affect the acquisition of the two other resources, and although the mechanism is different, the importance of parent's key skills is only amplified. 
Figure 4: Structural equation model including grandparental education

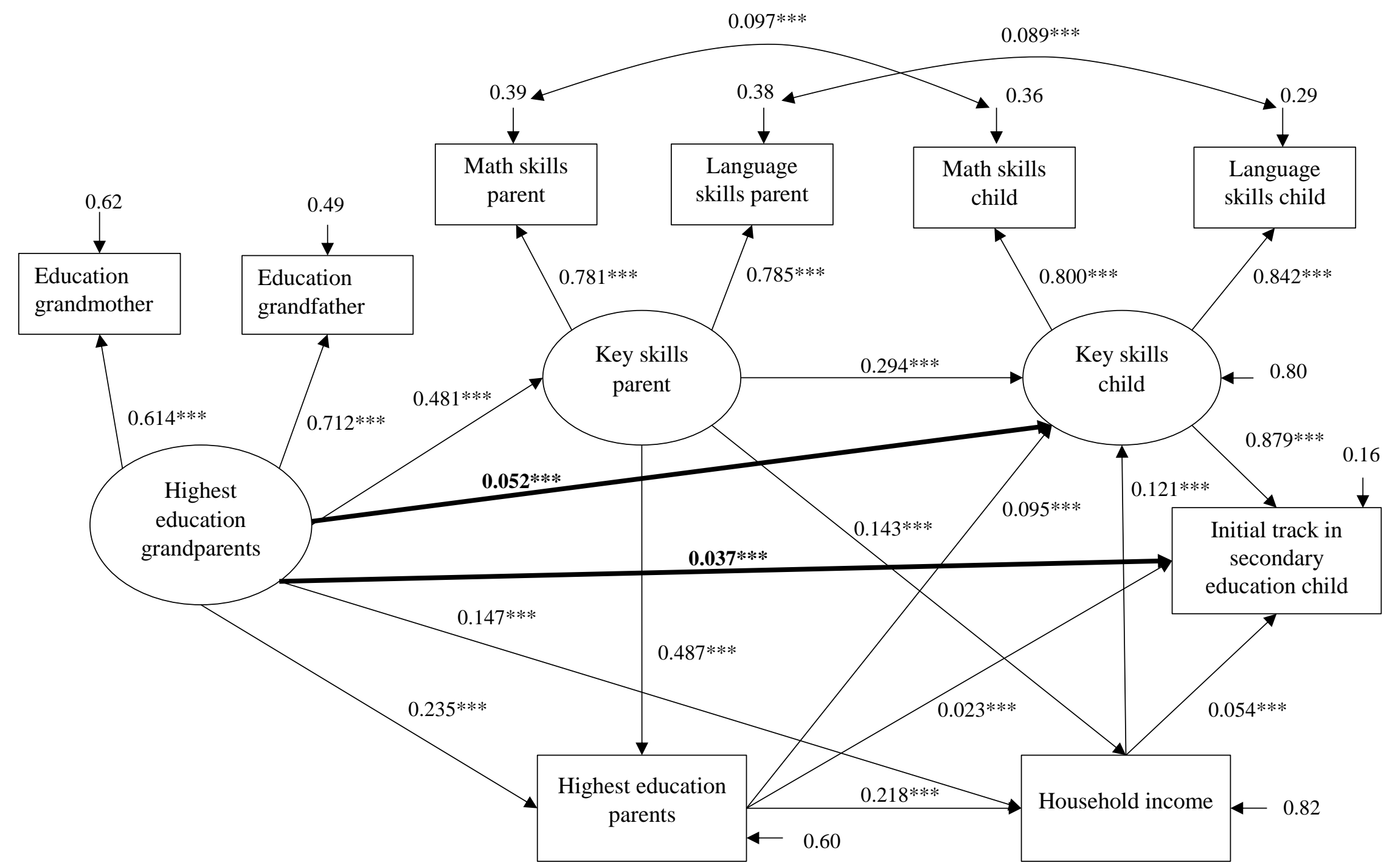

Source: ITS dataset; $N=25,287$; Notes: Standardized model coefficients are displayed; the standard errors are provided in Table S8 of the Supplementary Material. RMSEA=0.015; CFI=0.999; TLI=0.997; SRMR=0.006; *p < 0.05; **p $<0.01 ; * * * p<0.001$ 
Finally, we ran a model in which we include grandparent's education as an indicator of the social capital of the family. We do this to check whether the effects of parent's resources are affected by the resources in the extended family. The model is presented in Figure 4. The results show that grandparents' education directly affect their grandchildren's key skills, and their initial track in secondary education, but the size of the effect is small ( 0.052 and 0.037 respectively). This finding confirms earlier research showing that the so-called legacy effect (Mare 2011) is small but present. But most importantly, our key parameters of interest are not substantially affected. For the effect of parent's key skills on children's key skills we observe a small decrease from 0.315 to 0.294 , for parent's softs skills a decrease from 0.104 to 0.095 and for family's financial resources from 0.127 to 0.121 .

\section{Heterogeneous effects}

We checked whether the intergenerational transmission of key skills differs across social groups. We looked at potential heterogeneous effects in the intergenerational transmission of key skills between different combinations of fathers, mothers, sons and daughters, low- versus high-income families and low- versus high-educated families. A summary of the results is presented in Table 4 (full results are shown in Tables B1 to B3 of Appendix B).

Table 4: Summary table heterogeneous effects intergenerational transmission of key skills

\begin{tabular}{|l|l|l|l|}
\hline Heterogeneous effects & & & \\
\hline Gender & $\mathbf{N}$ & Estimate & Wald-test \\
\hline Mother \& daughter & & & \\
\hline Mother \& son & 6,868 & $0.310^{* * *}$ & \\
\hline Father \& daughter & 6,699 & $0.342 * * *$ & \\
\hline Father \& son & 5,868 & $0.307 * * *$ & \\
\hline & 5,852 & $0.290^{* * *}$ & n.s. \\
\hline Household income & & & \\
\hline Low income & 10,741 & $0.304 * * *$ & \\
\hline High income & 14,302 & $0.313^{* * *}$ & n.s. \\
\hline & & & \\
\hline Education & & & \\
\hline Low education & 7,259 & $0.281 * * *$ & \\
\hline High education & 17,081 & $0.282^{* * *}$ & $*$ \\
\hline
\end{tabular}

Source: ITS dataset; Standardized model coefficients are displayed; $n . s .=$ not significant; $* p<0.05 ; * * p<$ $0.01 ; * * *<0.001$

Overall, the Wald-tests indicate that the models do not differ significantly between the social groups with one exception. The model for low-educated parents is significantly different from the model for high-educated parents. As Table B1 in Appendix B shows, this is driven by other parameters in the model, such as the effect of parent's key skills on education parent, and the effect of education parent on household income. Most importantly, our parameter of interest (the effect of parent's key skills on 
their children's key skills) is not different. That also hold for the other groups, with a small exception. In the case of mother and sons, we find a slightly higher estimate (0.342). Overall, we conclude that the model presented in Figure 3 holds for the different subgroups as well.

\section{Robustness checks}

Apart from the robustness checks that we mentioned earlier (see results in Supplementary Material) we ran two alternative models to scrutinize our results. A first robustness analyses checks whether the role of skills is underestimated, because we have not measured all relevant skills. Moreover, the key skills that we did measure contain measurement error. Although the issue of measurement error is partly addressed in the SEM model, this might still be a concern. To the extent that measurement error is more severe in the case of measuring parent's key skills and less in the case of the other components in the model (i.e., education and income of parents), and this likely the case, the effects associated with key skills of the parents will be underestimated and the role of the other resources will be overestimated. In Figure B1 of Appendix B, we present the results of an additional analysis, in which we assess to which extent this is the case. As explained earlier, the allocation to a track in secondary education is based on the student's score on the national (CITO) test and the primary school teacher's advice, with the teacher's advice playing the dominant role. This advice is partly based on the test score, but also teacher's expectation whether the student will succeed at the advised track in secondary education. This can be based on a range of factors, varying from non-cognitive skills like study motivation and perseverance as well as results on earlier tests taken at school. ${ }^{13}$ The teacher can use the latter if he or she thinks that the student was over- or underperforming on the national test (e.g., because he or she had a bad day). We use teacher's advice to construct a variable that picks up other relevant skills (not measured by the test) as well as teacher's possible corrections for measurement error in the test. This teacher's advice is available for both parents and children. We use a regression analysis to assess these other aspects of the teacher's advice which we define as the residual in the teacher's advice after controlling for student's test performance. The results of this additional analysis do not affect the previous conclusions on the relative importance of skills. Although other skills, picked up by this teacher's advice, play an important role in the allocation to the track in secondary education, the intergenerational transmission of these other skills is quite low: the effect size is only 0.059. The combined effect of key skills and other skills in the intergenerational transmission of skills is somewhat higher (0.337) than the effect presented in Figure 2 (0.315), but the difference is not very substantial. This means that there is little reason to believe that the role of key skills in IEO is seriously underestimated.

\footnotetext{
${ }^{13}$ The teacher's advice is also known to be biased towards girls and students coming from high-SES families (Timmermans et al. 2018). This might lead to an overestimation of the role of parent's key skills.
} 
The strong intergenerational transmission of key skills suggests that part of this may be related to intelligence (and related genetic differences) rather than key skills acquired at school. To check this, we ran a model in which we included a measure of intelligence for the parents. When the cohorts started, parents were not only tested on their language and math skills, but also took an intelligence test. We checked whether our findings would differ after including this intelligence score in the model. Results are presented Figure B2 of Appendix B. The results indicate that the effects of parent's key skills, soft skills and financial resources on their children's key skills and allocation to a track in secondary education are hardly affected by the inclusion of parent's intelligence score. As one would expect, the intelligence score has a strong and significant effect on parent's key skills (0.401). But all other effects of parent's intelligence (on achieved education, household income, and children's key skills) are small and non-significant. The only effect that is barely significant $(p<0.10)$ is an effect of 0.015 on children's key skills. All in all, the model clearly demonstrates that our skill measure is not simply an intelligence measure, but rather captures acquired key skills in math and language that are crucial to be successful in education and transmitted from parents to their offspring.

\section{Conclusions}

For decades, researchers tried to gain a deeper understanding of the transmission of education to shed light on IEO and social mobility. In doing so, the aim has been to get insight in the underlying drivers of intergenerational transmission of education. These drivers can stem from three types of parental resources: parent's key skills (i.e., proficiency in important domains like math and language), parent's soft skills (i.e., the skills needed to navigate successfully in education), and parent's financial resources. To date, scholars have not been able to accurately distinguish the effects of these types of resources. In particular, the intergenerational transmission of key skills was underexposed due to the absence of adequate data. In this study, we contribute to the existing literature by including a direct measure of key skills of parents and their offspring. We developed a unique and unparalleled dataset, the ITS dataset, that includes parent's and children's key skills measured with the same test at age 12 . The tests are taken in the domains of math and language. This information is linked to detailed information on the educational pathways and household income. In previous research (Kraaykamp and van Eijck 2010), parent's educational attainment was used as a proxy for both their key skills and their soft skills. Our assumption is that after controlling for intergenerational transmission of key skills and the financial resources, the remaining effect of parent's education mainly captures the effect of their soft skills. Using structural equation modelling, the direct and indirect effects of the different family resources (parent's key skills, parent's soft skills, and parent's financial resources) on the offspring's educational outcomes were estimated. 
As previous research already showed, children's skill proficiency in language and math at age 12 are highly predictive for their allocation to a track in secondary education. Looking at the parental resources affecting children's key skills, we showed that these are mainly affected by parent's key skills. One standard deviation increase in parent's key skills is associated with almost one-third of a standard deviation increase in the key skills of their offspring. This finding is a substantial step in unravelling the intergenerational transmission of education. It indicates that the main mechanism in this process is the intergenerational transmission of key skills.

One concern that might arise is that the key skills of parents and their offspring are simply an indicator of their intelligence (Marks 2019; Marks 2021). As intelligence is partly genetic, this would affect the malleability of children's key skills and thus the possibility to increase educational mobility. As an additional check, we included parent's intelligence in the model. The results show that even though intelligence of parents affects their own key skills, it does not substantially affect the intergenerational transmission of these skills. This finding demonstrates, in line with previous research (Bartels et al. 2002; Van Boxtel, Engelen and de Wijs 2011), that our skill measures are not simply a measure of intelligence, but grasp the knowledge and skills in two key-domains in the world of education: math and language.

While other studies hinted at possible heterogeneity in the intergenerational transmission of key skills (De Coulon et al. 2011), we found little evidence that this is the case. We found no substantial differences in the intergenerational transmission of skills between fathers to sons, fathers to daughters, mothers to sons or mothers to daughters. Nor did we find substantial differences in the intergenerational transmission of key skills between low- and high-income families or low- and high-educated parents.

This means that our conclusion that key skills in the family is the most important mechanism driving IEO is robust. The intergenerational transmission of key skills accounts for 50-60\% of the effect of all measured resources available in the family. Nevertheless, this does not imply that the other two mechanisms, parent's soft skills, and parent's financial resources, are not relevant. On the contrary, together these two forms of resources have a combined effect on children's key skills and initial educational outcomes that is almost as strong as the effect of parent's key skills. The role of financial resources available to the family is a bit stronger than the role of parent's soft skills, accounting for some $25-30 \%$ of the total effect of family resources, with parent's soft skills taking up some $20-25 \%$.

The findings illustrate why IEO is so pervasive and did not substantially decline in the second half of the last century, even though success in education got increasingly dependent on merits instead origin. This adverse effect of a meritocracy was already recognized in the 1950s by Michael Young in his prophetic essay The Rise of the Meritocracy (Young 1958). His critical view on the meritocracy was echoed in a recent publication by Sandel (2020). In his view, the meritocracy generates 'winners' and 'losers' based on diplomas, which are easier to obtain for by the fortunate that have high-educated 
parents themselves. Social mobility is restricted not by inheritance of social positions in an aristocracy, but by credentialism in a parentocracy (Brown 1990). Markovits (2019) goes even further by arguing that meritocracy has become what it was conceived to resist: a mechanism for the concentration and dynastic transmission of wealth and privilege across generations. In this view, a strong intergenerational transmission of skills is not the result of deviations or retreats from meritocracy but rather stems directly from meritocracy's successes. High-skilled parents know how important skills are and use this to help their offspring succeed in education.

What are the possible policy implications of our findings? Previous research already showed that key skills are predictive for a range of individual economic and non-economic outcomes (e.g., Hanushek et al. 2015; Levels et al. 2014; McIntosh and Vignoles 2001). On top of that, we now demonstrated evidence for a strong intergenerational transmission of these key skills. Even if a substantial part of this intergenerational transmission would be genetic, this does not imply interventions would be pointless as Harden (2021) argued in her recent book The Genetic Lottery. It makes it even more crucial that interventions aiming to increase social mobility and equal educational opportunities should focus on stimulating these key skills among disadvantaged youth in early childhood or during primary education. This recommendation fits well with evidence from economic literature (Cunha et al. 2010; Heckman 2006), stating that investment in skill development in early childhood is more beneficial than interventions later in life. The benefits of this early investment in skill formation are particularly effective if they focus specifically on disadvantaged children. As we now found strong evidence for the intergenerational transmission of key skills, the returns to early childhood interventions are in fact underestimated. These interventions can also affect the skills of their offspring, leading to a multiplier effect in reducing inequality for future generations. This possible multiplier effect means that the social returns of investments in skills at an early age may be even higher than previously thought.

It is also important to stress the crucial role of schools here. The strong intergenerational transmission of skills does not imply that schools do not matter. The worldwide closure of schools during the pandemic made crystal clear what happens if schools are hampered in their skills development task. The school closure led to a significant decrease in learning growth (Blainey, Hiorns and Hannay 2020; Engzell, Frey and Verhagen 2021; Maldonado and De Witte 2021), specifically for children from disadvantaged families (Haelermans et al. forthcoming). This means that in the absence of schools, the skills gap between children from low-skilled and high-skilled parents would have been even stronger. Similarly, the re-opening of the schools in the second half of 2020 made it possible for many children to catch up again (Haelermans et al. 2021). This is exemplary to what schools can achieve and underlines that key skills such as math and literacy are malleable (Aucejo and James 2021). Moreover, there is substantial evidence that targeted interventions, such as High Doses Tutoring or Summer schools, are effective interventions to increase math and language skills for disadvantaged youth (De Ree et al. 2021; Fryer and Howard-Noveck 2020). 
The importance of key skills is even bigger, as parent's key skills also provide the basis for their acquisition of soft skills and financial resources. But the underlying mechanism how they affect children's skills and educational outcomes is different. In the case of parent's soft skills, it is related to things like positive norms and values towards education, familiarity with the culture at school and knowledge about the educational system, while in the case of financial resources, it is related to providing a stimulating learning environment in terms of equipment and extra tuition. Both mechanisms are not the strongest drivers of IEO, but both are substantial and together their impact is as large as the impact of parent's key skills. Moreover, there is a tendency that the role of these two mechanisms is growing due to increasing school segregation (Boterman et al. 2019; Reardon and Owens 2014; Vogels, Turkenburg and Herweijer 2021), difference in school quality and the emergence of elite schools (Merry and Boterman 2020), the increasing role of shadow education (Bray 2011) and increase in tuition fees (OECD 2020). This implies that policy measures should also be aimed at decreasing the negative impact for children coming from families with low soft skills and/or financial resources. In this case, effective interventions are likely aimed at increasing parental engagement and involvement (Kim and Hill 2015; Sénéchal and Young 2008) or in offering grants for disadvantaged students, lowering tuition fees, or providing free learning equipment (Bloome et al. 2018). 


\section{Funding}

We gratefully acknowledge a grant received from the Dutch Ministry of Education, Culture and Science and the Netherlands Initiative for Education Research (NRO: grant 405-17-900).

\section{Acknowledgements}

This paper is part of the Intergenerational Transmission of Skills (ITS) program carried out at the Research Centre for Education and the Labour Market (see project link). We gratefully acknowledge the comments on earlier drafts received by Per Bles, Arie Glebbeek, Rick Hanushek, Carla Haelermans, Tim Huijts, Suzanne de Leeuw, Guido Schwerdt, Stan Vermeulen, Herman van de Werfhorst and Simon Wiederhold. 


\section{References}

Adermon, Adrian, Mikael Lindahl and Mårten Palme. 2021. "Dynastic Human Capital, Inequality, and Intergenerational Mobility." American Economic Review 111(5):1523-48.

Anderson, Lewis, R. , Paula Sheppard and Christiaan W.S. Monden. "Grandparent Effects on Educational Outcomes: A Systematic Review." Sociological Science 5(6):114-42.

Anger, Silke and Guido Heineck. 2010. "Do Smart Parents Raise Smart Children? The Intergenerational Transmission of Cognitive Abilities." Journal of Population Economics 23(3):1105-32.

Anger, Silke. 2012. "The Intergenerational Transmission of Cognitive and Non-Cognitive Skills During Adolescence and Young Adulthood." SOEPpapers on Multidisciplinary Panel Data Research. Deutsches Institut für Wirtschaftsforschung (DIW), Berlin.

Aucejo, Esteban and Jonathan James. 2021. "The Path to College Education: The Role of Math and Verbal Skills." Journal of Political Economy 129(10):2905-46.

Barone, Carlo. 2006. "Cultural Capital, Ambition and the Explanation of Inequalities in Learning Outcomes: A Comparative Analysis." Sociology 40(6):1039-58.

Bartels, Meike, Marjolein JH Rietveld, G Caroline M Van Baal and Dorret I Boomsma. 2002. "Heritability of Educational Achievement in 12-Year-Olds and the Overlap with Cognitive Ability." Twin Research and Human Genetics 5(6):544-53.

Bentler, P. M. 1990. "Comparative Fit Indexes in Structural Models." Psychological bulletin 107(2):238-46.

Björklund, Anders, Karin Hederos Eriksson and Markus Jäntti. 2010. "IQ and Family Background: Are Associations Strong or Weak?". The B.E. Journal of Economic Analysis \& Policy 10(1).

Black, S. E., P. J. Devereux and K. G. Salvanes. 2005. "Why the Apple Doesn't Fall Far: Understanding Intergenerational Transmission of Human Capital." American Economic Review 95(1):437-49.

Black, Sandra E and Paul J Devereux. 2011. "Recent Developments in Intergenerational Mobility." Handbook of Labor Economics 4:1487-541.

Black, Sandra E., Paul J. Devereux and Kjell G. Salvanes. 2009. "Like Father, Like Son? A Note on the Intergenerational Transmission of IQ Scores." Economics Letters 105(1):138-40.

Blainey, K, C Hiorns and T Hannay. 2020. "The Impact of Lockdown on Children's Education: A Nationwide Analysis." Banbury, Hodder Education.

Blau, Peter M and Otis Dudley Duncan. 1967. The American Occupational Structure. New York: Wiley.

Bloome, Deirdre, Shauna Dyer and Xiang Zhou. 2018. "Educational Inequality, Educational Expansion, and Intergenerational Income Persistence in the United States." American Sociological Review 83(6):1215-53.

Bol, Thijs and Herman G. van de Werfhorst. 2013. "Educational Systems and the Trade-Off between Labor Market Allocation and Equality of Educational Opportunity." Comparative Education Review.

Borghans, L., A. L. Duckworth, J. Heckman and B. J. ter Weel. 2008. "The Economics and Psychology of Personality Traits." Journal of Human Resources 43(4):972-1059.

Borgonovi, Francesca, Artur Pokropek and Joshua L. Rosenbloom. 2016. "Education and SelfReported Health: Evidence from 23 Countries on the Role of Years of Schooling, Cognitive Skills and Social Capital." PLOS ONE 11(2):e0149716.

Bosker, R. and R. D. Velden. 1989. "Schooleffecten En Rendementen." Pp. 25-40 in Jongeren in School En Beroep, edited by J. van Damme and J. Dronkers. Amsterdam: Swets \& Zeitlinger.

Boterman, Willem, Sako Musterd, Carolina Pacchi and Costanzo Ranci. 2019. "School Segregation in Contemporary Cities: Socio-Spatial Dynamics, Institutional Context and Urban Outcomes." Urban Studies 56(15):3055-73.

Bourdieu, Pierre and J. C. Passeron. 1977. Reproduction in Education, Society and Culture. Translated by R. Nice. London: Sage.

Bourdieu, Pierre. 1984. Distinction: A Social Critique of the Judgement of Taste. Translated by R. Nice. Cambridge, Massachusetts: Harvard University Press. 
Bourdieu, Pierre. 1985. "The Social Space and the Genesis of Groups." Theory and Society 14(6):72344.

Bray, Mark. 2011. "The Challenge of Shadow Education: Private Tutoring and Its Implications for Policy Makers in the European Union." Luxembourg: European Commission.

Bray, Mark. 2020. "Shadow Education in Europe: Growing Prevalence, Underlying Forces, and Policy Implications." ECNU Review of Education: 4: 442-475.

Breen, Richard and Jan O. Jonsson. 2005. "Inequality of Opportunity in Comparative Perspective: Recent Research on Educational Attainment and Social Mobility." Annual Review of Sociology 31:223-43.

Breen, Richard and Walter Müller. 2020. Education and Intergenerational Social Mobility in Europe and the United States. Stanford, California: Stanford University Press.

Brown, Phillip. 1990. "The 'Third Wave': Education and the Ideology of Parentocracy." British Journal of Sociology of Education 11(1):65-86.

Brown, Sarah, Steven McIntosh and Karl Taylor. 2011. "Following in Your Parents' Footsteps? Empirical Analysis of Matched Parent-Offspring Test Scores* Empirical Analysis of ParentOffspring Test Scores." Oxford Bulletin of Economics and Statistics 73(1):40-58.

Calarco, J. M. 2014. "Coached for the Classroom: Parents' Cultural Transmission and Children's Reproduction of Educational Inequalities." American Sociological Review 79(5):1015-37.

Coleman, James S. 1988. "Social Capital in the Creation of Human Capital." American Journal of Sociology 94:S95-S120.

Cunha, Flavio and James Heckman. 2007. "The Technology of Skill Formation." The American Economic Review 97(2):31-47.

Cunha, Flavio, James J. Heckman and Susanne M. Schennach. 2010. "Estimating the Technology of Cognitive and Noncognitive Skill Formation." Econometrica 78(3):883-931.

Davies, Scott and Jessica Rizk. 2018. "The Three Generations of Cultural Capital Research: A Narrative Review." Review of Educational Research 88(3):331-65.

De Coulon, Augustin, Elena Meschi and Anna Vignoles. 2011. "Parents' Skills and Children's Cognitive and Non-Cognitive Outcomes." Education Economics 19(5):451-74.

De Graaf, Paul M. 1986. "The Impact of Financial and Cultural Resources on Educational Attainment in the Netherlands." Sociology of Education 59(4):237-46.

De Ree, Joppe, Mario A Maggioni, Bowen Paulle, Domenico Rossignoli and Dawid Walentek. 2021. "High Dosage Tutoring in Pre-Vocational Secondary Education: Experimental Evidence from Amsterdam." SocArXiv.

DiMaggio, Paul. 1982. "Cultural Capital and School Success: The Impact of Status Culture Participation on the Grades of U.S. High School Students." American Sociological Review 47(2):189-201.

Duckworth, Angela L. and Martin E. P. Seligman. 2005. "Self-Discipline Outdoes IQ in Predicting Academic Performance of Adolescents." Psychological Science 16(12):939-44.

Engzell, P., A. Frey and M. D. Verhagen. 2021. "Learning Loss Due to School Closures During the Covid-19 Pandemic." Proceedings of the National Academy of Sciences of the United States of America 118(17).

Farkas, George. 2003. "Cognitive Skills and Noncognitive Traits and Behaviors in Stratification Processes." Annual Review of Sociology 29(1):541-62.

Feron, Eva, Trudie Schils and Bas ter Weel. 2016. "Does the Teacher Beat the Test? The Additional Value of the Teacher's Assessment in Predicting Student Ability." De Economist 164(4):391418.

Fischbach, Antoine, Ulrich Keller, Franzis Preckel and Martin Brunner. 2013. "Pisa Proficiency Scores Predict Educational Outcomes." Learning and Individual Differences 24:63-72.

Forster, A. G. and H. G. Van de Werfhorst. 2020. "Navigating Institutions: Parents' Knowledge of the Educational System and Students' Success in Education." European Sociological Review 36(1).

Fryer, Roland G. and Meghan Howard-Noveck. 2020. "High-Dosage Tutoring and Reading Achievement: Evidence from New York City." Journal of Labor Economics 38(2):421-52. 
Ganzeboom, Harry, B. G., Donald J. Treiman and Wout C. Ultee. 1991. "Comparative Intergenerational Stratification Research: Three Generations and Beyond." Annual Review of Sociology 17:277-302.

Grätz, M., K. J. Barclay, N. Wiborg Ø, T. H. Lyngstad, A. Karhula, J. Erola, P. Präg, T. Laidley and D. Conley. 2021. "Sibling Similarity in Education across and within Societies." Demography 58(3):1011-37..

Haelermans, Carla, Timo Huijgen, Madelon Jacobs, Mark Levels, Rolf van der Velden, Lynn van Vugt and Sanne van Wetten. 2020. "Using Data to Advance Educational Research, Policy and Practice: Design, Content and Research Potential of the Netherlands Cohort Study on Education." European Sociological Review 36(4):643-62.

Haelermans, Carla, Rolf van der Velden, Bas Aarts, Ineke Bijlsma, Madelon Jacobs, Chayenne Smeets, Lynn van Vugt and Sanne van Wetten. 2021. Balans Na Anderhalf Jaar: Vertraging Leergroei Het Grootst Voor Rekenenwiskunde: Nationaal Regieorgaan Onderwijsonderzoek.

Haelermans, Carla, Roxanne Korthals, Madelon Jacobs, Suzanne de Leeuw, Stan Vermeulen, Lynn van Vugt, Bas Aarts, Tijana Prokic-Breuer, Rolf van der Velden, Sanne van Wetten and Inge de Wolf. forthcoming. "Sharp Increase in Inequality in Education in Times of the Covid-19Pandemic." Preprint. PLOS ONE. doi: 10.31219/osf.io/78fje

Hanushek, Eric A., Guido Schwerdt, Simon Wiederhold and Ludger Woessmann. 2015. "Returns to Skills around the World: Evidence from Piaac." European Economic Review 73:103-30.

Hanushek, Eric A., Babs Jacobs, Guido Schwerdt, Rolf van der Velden, Stan Vermeulen and Simon Wiederhold. 2021. "The Intergenerational Transmission of Skills: An Investigation of the Causal Impact of Families on Student Outcomes."

Hanushek, Eric Alan and Ludger Woessmann. 2011. "The Economics of International Differences in Educational Achievement." Handbook of the economics of education.

Harden, Kathryn Paige. 2021. The Genetic Lottery: Why DNA Matters for Social Equality. Princeton: Princeton University Press.

Hart, Sara A., Callie Little and Elsje van Bergen. 2021. "Nurture Might Be Nature: Cautionary Tales and Proposed Solutions." npj Science of Learning 6(1).

Hauser, Robert M. and Raymond Sin-Kwok Wong. 1989. "Sibling Resemblance and Intersibling Effects in Educational Attainment." Sociology of Education 62(3):149-71.

Heckman, James J. 2006. "Skill Formation and the Economics of Investing in Disadvantaged Children." Science 312(5782):1900-02.

Huang, Jin. 2013. "Intergenerational Transmission of Educational Attainment: The Role of Household Assets." Economics of Education Review 33:112-23.

Jacobs, Babs, Stan Vermeulen and Rolf Van der Velden. 2021a. "The Intergenerational Transmission of Skills Dataset." Maastricht: Research Centre for Education and the Labour Market (ROA).

Jacobs, Madelon, Rolf van der Velden and Lynn van Vugt. 2021b. "Does Lowering the Bar Help? Results from a Natural Experiment in High-Stakes Testing in Dutch Primary Education." No. 004. Maastricht University: Research Centre for Education and the Labour Market (ROA).

Jaeger, M. M. 2012. "The Extended Family and Children's Educational Success." American Sociological Review 77(6):903-22.

Kakarmath, Sujay, Vanessa Denis, Marta Encinas-Martin, Francesca Borgonovi and S. V. Subramanian. 2018. "Association between Literacy and Self-Rated Poor Health in 33 Highand Upper Middle-Income Countries." International Journal of Public Health : International Journal of Public Health 63(2):213-22.

Kalmijn, Matthijs and Gerbert Kraaykamp. 1996. "Race, Cultural Capital, and Schooling: An Analysis of Trends in the United States." Sociology of Education 69(1):22-34.

Kim, Sung won and Nancy E. Hill. 2015. "Including Fathers in the Picture: A Meta-Analysis of Parental Involvement and Students' Academic Achievement." Journal of Educational Psychology 107(4):919-34.

Kingston, Paul W. 2001. "The Unfulfilled Promise of Cultural Capital Theory." Sociology of Education 74:88-99.

Klein, Markus and Michael Kühhirt. 2021. "Direct and Indirect Effects of Grandparent Education on Grandchildren's Cognitive Development: The Role of Parental Cognitive Ability." Life Course Centre Working Paper (2021-06). 
Kloosterman, Rianne, Stijn Ruiter, Paul M. De Graaf and Gerbert Kraaykamp. 2009. "Parental Education, Children's Performance and the Transition to Higher Secondary Education: Trends in Primary and Secondary Effects over Five Dutch School Cohorts (1965-99)." The British Journal of Sociology 60(2):377-98.

Knighton, Tamara and Patrick Bussière. 2006. "Educational Outcomes at Age 19 Associated with Reading Ability at Age 15." Ottawa, Canada: Statistics Canada.

Kraaykamp, Gerbert and Koen van Eijck. 2010. "The Intergenerational Reproduction of Cultural Capital: A Threefold Perspective." Social Forces 89(1):209-31.

Lamont, Michele and Annette Lareau. 1988. "Cultural Capital: Allusions, Gaps and Glissandos in Recent Theoretical Developments." Sociological Theory 6(2):153-68.

Lareau, A. and E. B. Weininger. 2003. "Cultural Capital in Educational Research: A Critical Assessment." Theory and Society 32(5/6):567-606.

Lehti, Hannu, Jani Erola and Antti O. Tanskanen. 2019. "Tying the Extended Family KnotGrandparents' Influence on Educational Achievement." European Sociological Review 35(1):29-48.

Lek, Kimberley Martine. 2020. Teacher Knows Best? On the (Dis)Advantages of Teacher Judgments and Test Results, and How to Optimally Combine Them: Utrecht University.

Levels, Mark, Rolf van der Velden and Jim Allen. 2014. "Educational Mismatches and Skills: New Empirical Tests of Old Hypotheses." Oxford Economic Papers 66(4):959-82.

Maldonado, Joana Elisa and Kristof De Witte. 2021. "The Effect of School Closures on Standardised Student Test Outcomes." British Educational Research Journal.

Mare, Robert D. 2011. "A Multigenerational View of Inequality." Demography 48(1):1-23.

Markovits, Daniel. 2019. The Meritocracy Trap : How America's Foundational Myth Feeds Inequality, Dismantles the Middle Class, and Devours the Elite. New York: Penguin Press.

Marks, Gary N. and Irma Mooi-Reci. 2016. "The Declining Influence of Family Background on Educational Attainment in Australia: The Role of Measured and Unmeasured Influences." Social Science Research 55:171-85.

Marks, Gary N. 2019. "Socioeconomic Background, Education, Cognitive Ability and Genetics: A Commentary on Bourne Et Al." Research in Social Stratification and Mobility 61:20-23.

Marks, Gary N. 2021. "Is the Relationship between Socioeconomic Status (Ses) and Student Achievement Causal? Considering Student and Parent Abilities." Educational Research and Evaluation:1-24.

Martin, John P. 2018. Skills for the 21st Century: Findings and Policy Lessons from the Oecd Survey of Adult Skills. Paris: OECD Publishing.

McIntosh, Steven and Anna Vignoles. 2001. "Measuring and Assessing the Impact of Basic Skills on Labour Market Outcomes." Oxford Economic Papers 53(3):453-81.

Merry, Michael S. and Willem Boterman. 2020. "Educational Inequality and State-Sponsored Elite Education: The Case of the Dutch Gymnasium." Comparative Education 56(4):522-46.

Modin, Bitte, Robert Erikson and Denny Vågerö. 2013. "Intergenerational Continuity in School Performance: Do Grandparents Matter?". European Sociological Review 29(4):858-70.

Moreno, Hector. 2021. "The Influence of Parental and Grandparental Education in the Transmission of Human Capital." Vol. 588. ECINEQ.

Mori, Izumi and David Baker. 2010. "The Origin of Universal Shadow Education: What the Supplemental Education Phenomenon Tells Us About the Postmodern Institution of Education." Asia Pacific Education Review 11(1):36-48.

Muthén, L.K. and B.O. Muthén. 2017. Mplus User's Guide. Eighth Edition. Los Angeles, CA: Muthén \& Muthén.

Nicoletti, Cheti and Birgitta Rabe. 2019. "Sibling Spillover Effects in School Achievement." Journal of Applied Econometrics 34(4):482-501

OECD. 2013. The Survey of Adult Skills. Paris: OECD Publishing.

OECD. 2020. Education at a Glance 2020: Oecd Indicators. Paris: OECD Publishing.

Ramlall, Indranarain. 2017. Applied Structural Equation Modelling for Researchers and Practitioners : Using R and Stata for Behavioural Research. Bingley, UK: Emerald Group Publishing Limited. 
Reardon, Sean F. and Ann Owens. 2014. "60 Years after "Brown": Trends and Consequences of School Segregation." Annual Review of Sociology 40:199-218.

Sacerdote, B. 2011. "Nature and Nurture Effects on Children's Outcomes: What Have We Learned from Studies of Twins and Adoptees?". Handbook of Social Economics 1(1 B):1-30.

Sandel, Michael J. 2020. The Tyranny of Merit : What's Become of the Common Good? New York: Farrar, Straus and Giroux.

Schneider, Daniel, Orestes P. Hastings and Joe LaBriola. 2018. "Income Inequality and Class Divides in Parental Investments." American Sociological Review 83(3):475-507.

Sénéchal, Monique and Laura Young. 2008. "The Effect of Family Literacy Interventions on Children's Acquisition of Reading from Kindergarten to Grade 3: A Meta-Analytic Review." Review of Educational Research 78(4):880-907.

Steiger, James H. 1990. "Structural Model Evaluation and Modification: An Interval Estimation Approach." Multivariate behavioral research 25(2):173-80.

Sullivan, Alice. 2001. "Cultural Capital and Educational Attainment." Sociology 35(4):893-912.

Treiman, Donald J. 1970. "Industrialization and Social Stratification." Sociological inquiry 40(2):20734.

Treiman, Donald J and Harry BG Ganzeboom. 2000. "The Fourth Generation of Comparative Stratification Research." in The International Handbook of Sociology, edited by S. R. Quah and A. Sales. London: Sage.

Tzanakis, Michael. 2011. "Bourdieu's Social Reproduction Thesis and the Role of Cultural Capital in Educational Attainment: A Critical Review of Key Empirical Studies." Educate 11(1):76-90.

Van Boxtel, Herman, Ronald Engelen and Anja de Wijs. 2011. "Wetenschappelijke Verantwoording Van De Eindtoets 2010." Arnhem: Cito.

Van der Velden, Rolf and Ineke Bijlsma. 2019. "Effective Skill: A New Theoretical Perspective on the Relation between Skills, Skill Use, Mismatches, and Wages." Oxford Economic PapersNew Series 71(1):145-65.

Vera-Toscano, Esperanza, Margarida Rodrigues and Patricia Costa. 2017. "Beyond Educational Attainment: The Importance of Skills and Lifelong Learning for Social Outcomes. Evidence for Europe from Piaac." European Journal of Education 52(2):217-31.

Vogels, Ria, Monique Turkenburg and Lex Herweijer. 2021. "Samen of Gescheiden Naar School: De Betekenis Van Sociale Scheiding En Ontmoeting in Het Voortgezet Onderwijs." The Hague: Sociaal en Cultureel Planbureau.

Vroom, Victor H. 1964. Work and Motivation. New York: Wiley.

Young, Michael. 1958. The Rise of the Meritocracy, 1870-2033: An Essay on Education and Equality. London: Thames and Hudson.

Zwier, Dieuwke, Sara Geven and Herman G. van de Werfhorst. 2021. "Social Inequality in Shadow Education: The Role of High-Stakes Testing." International Journal of Comparative Sociology. 


\section{Appendix A}

Additional information on the ITS-dataset

Table A1 shows an overview of the merging process in more detail. This table demonstrates that household information is available for most of the parents and children in our final dataset (respectively $35 \%$ (1977), 45\% (1983) and 23\% (1989) of the original education cohorts). For most children, educational information is available from the Netherlands Cohort Study on Education (NCO) or register information on enrolments in education.

Table A1. Overview combining all data in the ITS-dataset

\begin{tabular}{|c|c|c|c|}
\hline & $\begin{array}{l}\text { Education cohort } \\
1977\end{array}$ & $\begin{array}{l}\text { Education cohort } \\
1983\end{array}$ & $\begin{array}{l}\text { Education cohort } \\
1989\end{array}$ \\
\hline A. Original file & 37,280 & 16,813 & 19,524 \\
\hline $\begin{array}{l}\text { B. Parents with } \\
\text { linkable ID }\end{array}$ & $\begin{array}{l}30,171 \\
(81 \% \text { of } A)\end{array}$ & $\begin{array}{l}14,764 \\
(88 \% \text { of } A)\end{array}$ & $\begin{array}{l}19,111 \\
(98 \% \text { of } A)\end{array}$ \\
\hline $\begin{array}{l}\text { C. Parents with test } \\
\text { data }\end{array}$ & $\begin{array}{l}25,462 \\
(69 \% \text { of } A)\end{array}$ & $\begin{array}{l}14,613 \\
(87 \% \text { of } A)\end{array}$ & $\begin{array}{l}18,015 \\
(92 \% \text { of } A)\end{array}$ \\
\hline E. With children & $\begin{array}{l}19,633 \text { parents } \\
(53 \% \text { of } A) \\
42,616 \text { children }\end{array}$ & $\begin{array}{l}11,315 \text { parents } \\
(67 \% \text { of } A) \\
24,330 \text { children }\end{array}$ & $\begin{array}{l}13,657 \text { parents } \\
(70 \% \text { of A) } \\
29,089 \text { children }\end{array}$ \\
\hline $\begin{array}{l}\text { F. Children with test } \\
\text { data }\end{array}$ & $\begin{array}{l}13,248 \text { parents } \\
(36 \% \text { of } A) \\
22,241 \text { children } \\
(52 \% \text { of } E)\end{array}$ & $\begin{array}{l}7,649 \text { parents } \\
(46 \% \text { of } A) \\
12,872 \text { children } \\
(53 \% \text { of } E)\end{array}$ & $\begin{array}{l}4,586 \text { parents } \\
(24 \% \text { of } A) \\
6,361 \text { children } \\
(22 \% \text { of } E)\end{array}$ \\
\hline $\begin{array}{l}\text { G. With household } \\
\text { income data }\end{array}$ & $\begin{array}{l}13,151 \text { parents } \\
(35 \% \text { of } A) \\
22,136 \text { children } \\
(52 \% \text { of } E)\end{array}$ & $\begin{array}{l}7,539 \text { parents } \\
(45 \% \text { of } A) \\
12,713 \text { children } \\
(52 \% \text { of } E)\end{array}$ & $\begin{array}{l}4,527 \text { parents } \\
(23 \% \text { of } A) \\
6,325 \text { children } \\
(22 \% \text { of } E)\end{array}$ \\
\hline $\begin{array}{l}\text { H. Children with } \\
\text { educational data }\end{array}$ & $\begin{array}{l}13,206 \text { parents } \\
(35 \% \text { of } A) \\
22,324 \text { children } \\
(52 \% \text { of } E)\end{array}$ & $\begin{array}{l}7,555 \text { parents } \\
(45 \% \text { of } A) \\
12,752 \text { children } \\
(52 \% \text { of } E)\end{array}$ & $\begin{array}{l}4,547 \text { parents } \\
(23 \% \text { of } A) \\
6,295 \text { children } \\
(22 \% \text { of } E)\end{array}$ \\
\hline
\end{tabular}



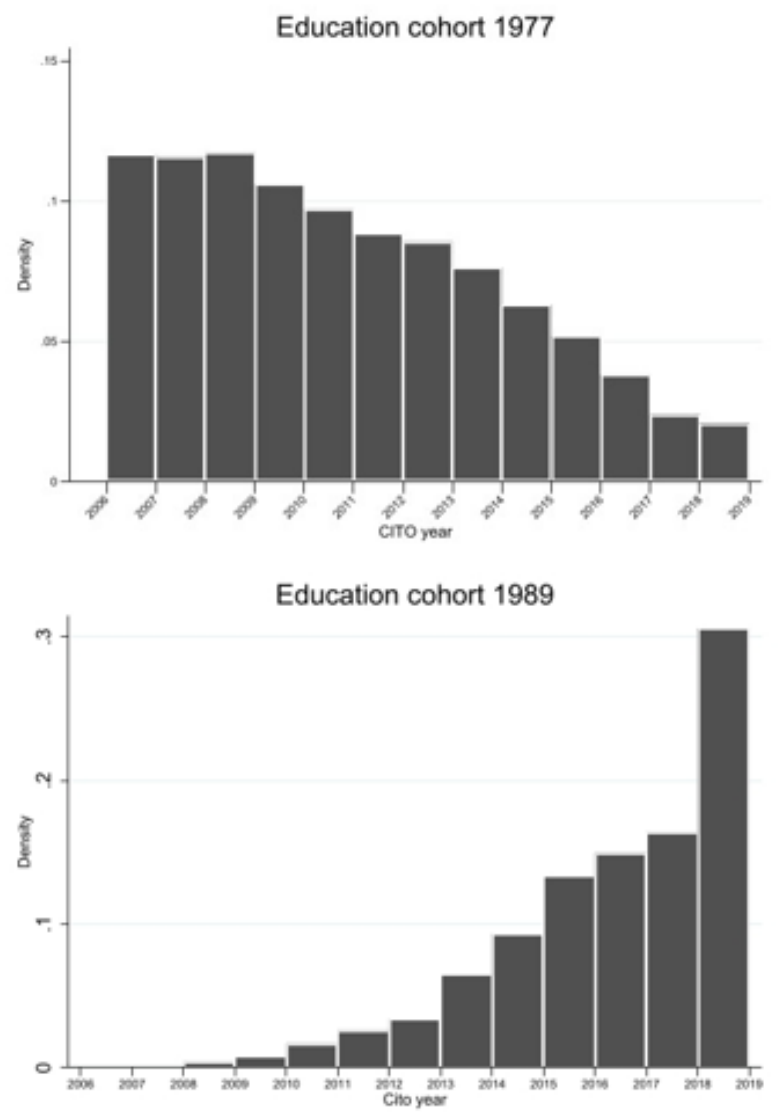

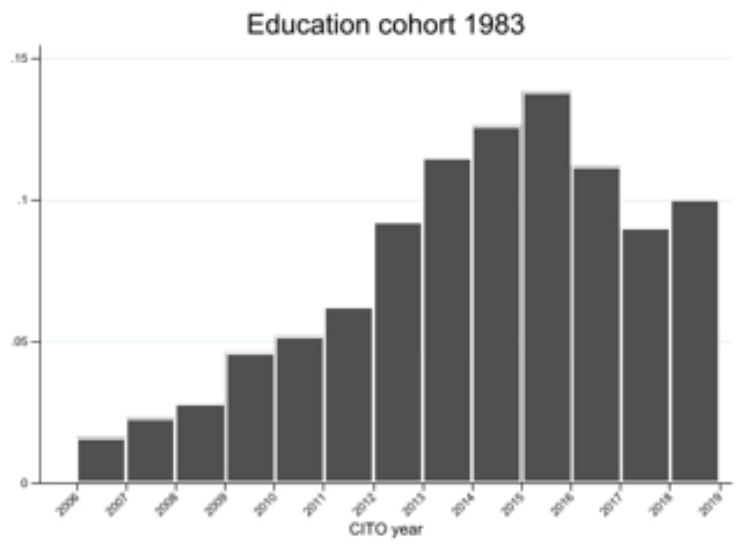

All education cohorts

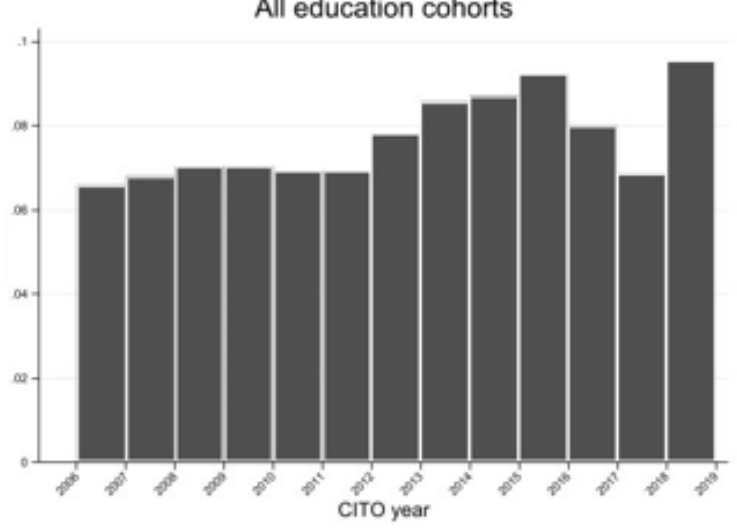

Source: ITS dataset $; N_{\text {cohort } 1977}=13,184 ; N_{\text {cohort } 1983}=7,563 ; N_{\text {cohort } 1989}=4,540$

Figure A2 shows the distribution of children by test year, for the three cohorts separately and for the combined sample. It clearly demonstrates that the cohorts are unbalanced regarding the timing of the test of their children. Most children of cohort 1977 took their test in 2006-2012, while most children in cohort 1989 took their test in 2016-2019. The distribution of the total sample is however evenly spread over the test years. 


\section{Appendix B: Additional analyses}

Table B1:Multigroup SEM-Model gender parent and gender child

\begin{tabular}{|c|c|c|c|c|c|c|c|c|c|c|c|c|}
\hline & Mother/Daughter & & & Mother/Son & & & Father/Daughter & & & Father/Son & & \\
\hline & Estimate & & S.E. & Estimate & & S.E. & Estimate & & S.E. & Estimate & & S.E. \\
\hline \multicolumn{13}{|l|}{ Skills parent BY } \\
\hline Language parent & 0.769 & $* * *$ & 0.007 & 0.766 & $* * *$ & 0.007 & 0.769 & $* * *$ & 0.007 & 0.779 & $* * *$ & 0.007 \\
\hline Math parent & 0.797 & $* * *$ & 0.007 & 0.792 & $* * *$ & 0.007 & 0.796 & $* * *$ & 0.007 & 0.802 & $* * *$ & 0.007 \\
\hline \multicolumn{13}{|l|}{ Skills child BY } \\
\hline Language child & 0.846 & $* * *$ & 0.005 & 0.821 & $* * *$ & 0.006 & 0.842 & $* * *$ & 0.005 & 0.823 & $* * *$ & 0.006 \\
\hline Math child & 0.804 & $* * *$ & 0.006 & 0.816 & $* * *$ & 0.005 & 0.798 & $* * *$ & 0.006 & 0.811 & $* * *$ & 0.006 \\
\hline \multicolumn{13}{|l|}{ Skills child ON } \\
\hline Skills parent & 0.310 & $* * *$ & 0.017 & 0.342 & $* * *$ & 0.018 & 0.307 & $* * *$ & 0.021 & 0.290 & $* * *$ & 0.020 \\
\hline Education parent & 0.113 & $* * *$ & 0.016 & 0.091 & $* * *$ & 0.016 & 0.102 & $* * *$ & 0.020 & 0.124 & $* * *$ & 0.019 \\
\hline Household income & 0.139 & $* * *$ & 0.013 & 0.113 & $* * *$ & 0.014 & 0.145 & $* * *$ & 0.015 & 0.108 & $* * *$ & 0.015 \\
\hline \multicolumn{13}{|c|}{ Education parent ON } \\
\hline Skills parent & 0.551 & $* * *$ & 0.011 & 0.543 & $* * *$ & 0.012 & 0.667 & $* * *$ & 0.011 & 0.636 & $* * *$ & 0.011 \\
\hline \multicolumn{13}{|c|}{ Household income ON } \\
\hline Skills parent & 0.190 & & 0.016 & 0.219 & & 0.017 & 0.175 & & 0.021 & 0.160 & & 0.020 \\
\hline Education parent & 0.249 & $* * *$ & 0.015 & 0.230 & $* * *$ & 0.015 & 0.277 & $* * *$ & 0.019 & 0.292 & $* * *$ & 0.018 \\
\hline \multicolumn{13}{|l|}{ Education child ON } \\
\hline Skills child & 0.885 & $* * *$ & 0.006 & 0.875 & $* * *$ & 0.007 & 0.892 & $* * *$ & 0.007 & 0.889 & $* * *$ & 0.007 \\
\hline Education parent & 0.029 & $* * *$ & 0.008 & 0.041 & $* * *$ & 0.009 & 0.044 & $* * *$ & 0.009 & 0.037 & $* * *$ & 0.009 \\
\hline Household income & 0.065 & $* * *$ & 0.008 & 0.069 & $* * *$ & 0.008 & 0.037 & $* * *$ & 0.009 & 0.066 & $* * *$ & 0.009 \\
\hline
\end{tabular}

Source: ITS dataset; $N_{\text {motherdaughter }}=6,868 ; N_{\text {motherson }}=6,699 ; N_{\text {fatherdaugther }}=5,868 ; N_{\text {fatherson }}=5,852 ;$ Notes: Standardized model coefficients are displayed $;$ Wald test $p-$

value $=0.07 ;$ RMSEA $=0.145 ; C F I=0.931 ; T L I=0.839 ;$ SRMR=0.0046; $* p<0.05 ; * * p<0.01 ; * * * p<0.001$ 
Table B2: Multigroup SEM-Model for parents with low and high household income

\begin{tabular}{|c|c|c|c|c|c|c|}
\hline & $\begin{array}{l}\text { High household } \\
\text { income }\end{array}$ & & & $\begin{array}{l}\text { Low household } \\
\text { income }\end{array}$ & & \\
\hline & Estimate & & S.E. & Estimate & & S.E. \\
\hline \multicolumn{7}{|l|}{ Skills parent BY } \\
\hline Language parent & 0.769 & $* * *$ & 0.005 & 0.763 & $* * *$ & 0.006 \\
\hline Math parent & 0.764 & $* * *$ & 0.005 & 0.785 & $* * *$ & 0.006 \\
\hline \multicolumn{7}{|l|}{ Skills child BY } \\
\hline Language child & 0.835 & $* * *$ & 0.004 & 0.835 & $* * *$ & 0.004 \\
\hline Math child & 0.790 & $* * *$ & 0.004 & 0.794 & $* * *$ & 0.004 \\
\hline \multicolumn{7}{|l|}{ Skills child ON } \\
\hline Skills parent & 0.313 & $* * *$ & 0.013 & 0.304 & $* * *$ & 0.014 \\
\hline Education parent & 0.096 & $* * *$ & 0.012 & 0.110 & $* * *$ & 0.013 \\
\hline Household income & 0.080 & $* * *$ & 0.009 & 0.055 & $* * *$ & 0.010 \\
\hline \multicolumn{7}{|c|}{ Education parent ON } \\
\hline Skills parent & 0.579 & $* * *$ & 0.008 & 0.534 & $* * *$ & 0.010 \\
\hline \multicolumn{7}{|c|}{ Household income ON } \\
\hline Skills parent & 0.131 & $* * *$ & 0.012 & 0.077 & $* * *$ & 0.014 \\
\hline Education parent & 0.207 & $* * *$ & 0.011 & 0.088 & $* * *$ & 0.013 \\
\hline \multicolumn{7}{|l|}{ Education child ON } \\
\hline Skills child & 0.889 & $* * *$ & 0.004 & 0.895 & $* * *$ & 0.005 \\
\hline Education parent & 0.037 & $* * *$ & 0.006 & 0.035 & $* * *$ & 0.007 \\
\hline Household income & 0.046 & $* * *$ & 0.005 & 0.015 & $*$ & 0.006 \\
\hline
\end{tabular}

Source: ITS dataset; $N_{\text {high }}=14,302 ; N_{\text {low }}=10,741$;

Notes: Standardized model coefficients are displayed; Wald test $p$-value=0.427; RMSEA=0.019; CFI=0.999;

$T L I=0.997 ;$ SRMR $=0.007 ; * p<0.05 ; * * p<0.01 ; * * * p<0.001$ 
Table B3: Multigroup SEM-Model for high- and low-educated parents

\begin{tabular}{|l|l|l|l|l|l|l|l|}
\hline & $\begin{array}{l}\text { High } \\
\text { education }\end{array}$ & & & $\begin{array}{l}\text { Low } \\
\text { education }\end{array}$ & & & \\
\hline & Estimate & & S.E. & Estimate & & S.E. & Estimate \\
\hline Skills parent BY & & & & & & & \\
\hline Language parent & 0.752 & $* * *$ & 0.005 & 0.692 & $* * *$ & 0.008 & 0.000 \\
\hline Math parent & 0.745 & $* * *$ & 0.006 & 0.758 & $* * *$ & 0.008 & 0.000 \\
\hline & & & & & & & \\
\hline Skills child BY & & & & & & & \\
\hline Language child & 0.833 & $* * *$ & 0.003 & 0.825 & $* * *$ & 0.005 & 0.000 \\
\hline Math child & 0.791 & $* * *$ & 0.004 & 0.782 & $* * *$ & 0.005 & 0.000 \\
\hline & & & & & & & \\
\hline Skills child ON & & & & & & & \\
\hline Skills parent & 0.281 & $* * *$ & 0.011 & 0.282 & $* * *$ & 0.014 & 0.000 \\
\hline Education parent & 0.089 & $* * *$ & 0.009 & 0.019 & & 0.013 & 0.139 \\
\hline Household income & 0.118 & $* * *$ & 0.009 & 0.132 & $* * *$ & 0.013 & 0.000 \\
\hline & & & & & & & \\
\hline Education parent ON & & & & & & & \\
\hline Skills parent & 0.478 & $* * *$ & 0.007 & 0.159 & $* * *$ & 0.017 & 0.000 \\
\hline & & & & & & & \\
\hline $\begin{array}{l}\text { Household income } \\
\text { ON }\end{array}$ & & & & & & & \\
\hline Skills parent & 0.155 & $* * *$ & 0.010 & 0.169 & $* * *$ & 0.014 & 0.000 \\
\hline Education parent & 0.225 & $* * *$ & 0.009 & 0.005 & & 0.012 & 0.706 \\
\hline & & & & & & & \\
\hline Education child ON & & & & & & & \\
\hline Skills child & 0.885 & $* * *$ & 0.004 & 0.896 & $* * *$ & 0.006 & 0.000 \\
\hline Education parent & 0.031 & $* * *$ & 0.005 & 0.009 & $* * *$ & 0.008 & 0.252 \\
\hline Household income & 0.065 & $* * *$ & 0.005 & 0.047 & $* * *$ & 0.008 & 0.000 \\
\hline
\end{tabular}

Source: ITS dataset; $N_{\text {high }}=17,081 ; N_{\text {low }}=7,259$;

Standardized model coefficients are displayed; Wald test $p$-value $=0.021 ; R M S E A=0.027 ; C F I=0.997$;

$T L I=0.993 ; S R M R=0.007 ; * p<0.05 ; * * p<0.01 ; * * * p<0.001$ 
Correction for other skills and measurement error

Figure B1: Structural equation model including parent's (key) skills, educational attainment and household income



Source: ITS dataset; $N=25,287 ;$ Notes: Standardized model coefficients are displayed; the standard errors are provided in Table S. of the Supplementary Material. RMSEA=0.038; CFI=0.993; TLI=0.983; SRMR=0.005; $* p<0.05 ; * * p<0.01 ; * * * p<0.001$ 


\section{Controlling for parent's intelligence}

Figure B2: Structural equation model including parent's intelligence at age 12

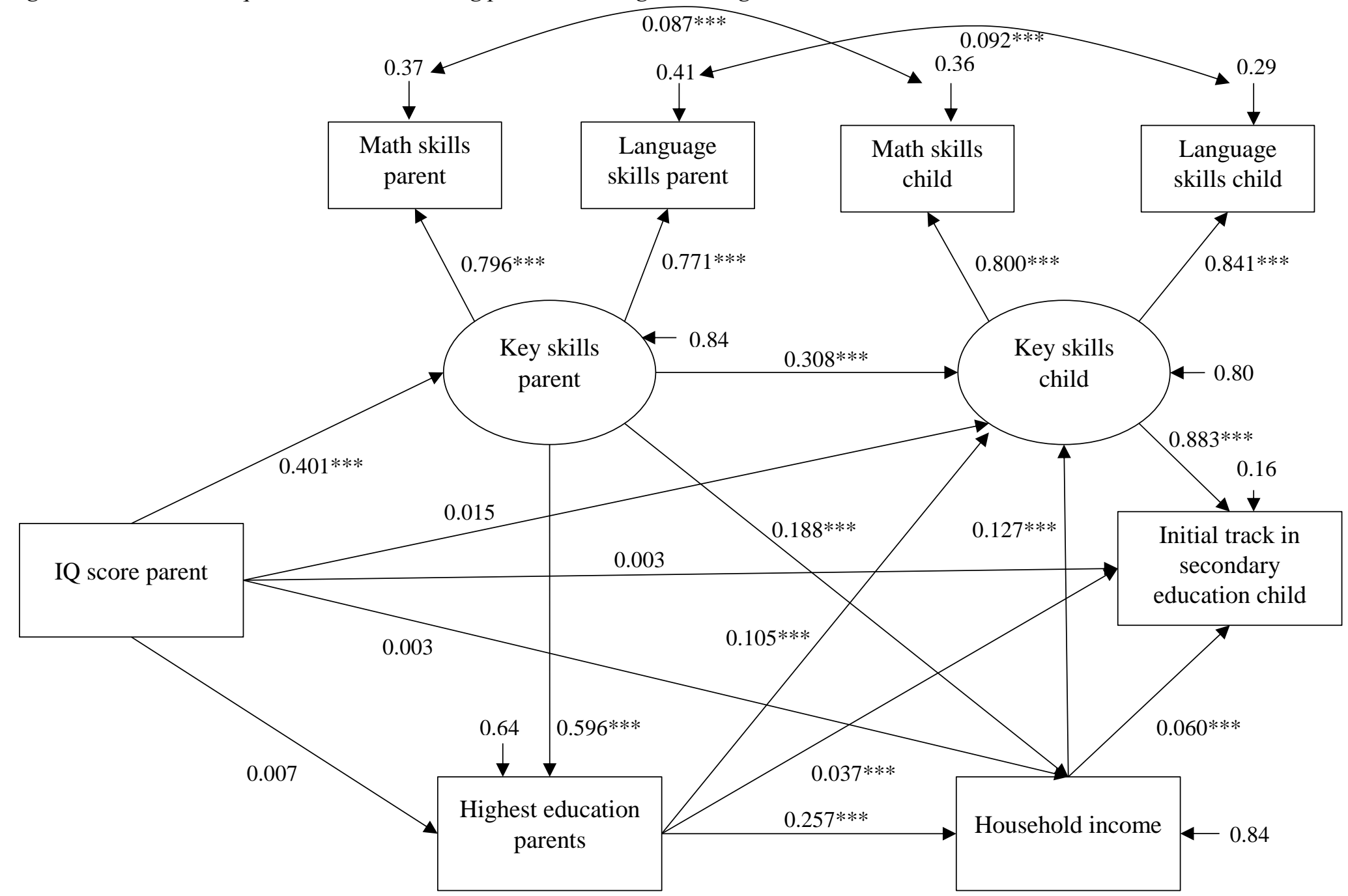

Source: ITS dataset; N=25,287; Notes: Standardized model coefficients are displayed; the standard errors are provided in Table S.. of the Supplementary Material. RMSEA $=0.025 ; C F I=0.998 ; T L I=0.994 ;$ SRMR $=0.006 ; * p<0.05 ; * * p<0.01 ; * * * p<0.001$ 


\section{Controlling for parent's intelligence}

Figure B2: Structural equation model including parent's intelligence at age 12

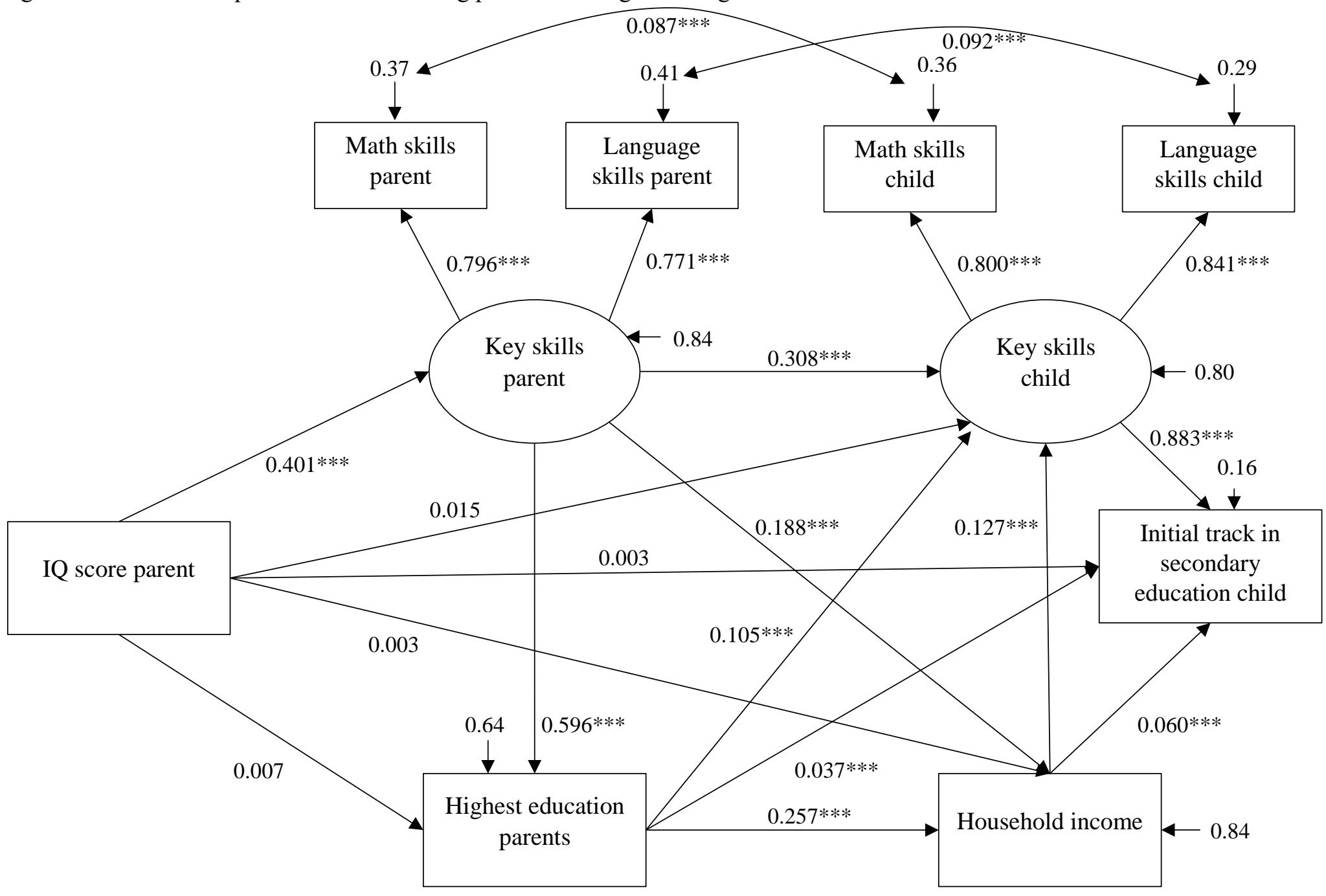


Source: ITS dataset; N=25,287; Notes: Standardized model coefficients are displayed; the standard errors are provided in Table S.. of the Supplementary Material. RMSEA=0.025; CFI=0.998; TLI=0.994; SRMR=0.006; * $<$ 0.05; ** $p<0.01 ; * * * p<0.001$ 